\title{
GEOLOGÍA DEL CUADRANTE TAPANTÍ (1:50 000), COSTA RICA
}

\author{
GEOLOGY OF TAPANTÍ QUADRANGLE (1:50 000), COSTA RICA
}

\author{
Dennis Sojo ${ }^{1,2,3 *}$, Percy Denyer ${ }^{2}$, Esteban Gazel ${ }^{4}$ y Guillermo E. Alvarado ${ }^{3,5}$ \\ ${ }^{1}$ Universidad de Zaragoza, apartado 50009. Pedro Cerbuna, Zaragoza, España. \\ ${ }^{2}$ Geotest S.A. Apdo. 1291-2050, San Pedro, San José, Costa Rica \\ ${ }^{3}$ Centro de Investigación en Ciencias Geológicas (UCR), San José, Costa Rica \\ ${ }^{4}$ Department of Geosciencies (Virginia Tech), Virginia, USA \\ ${ }^{5}$ Instituto Costarricense de Electricidad (ICE), San José, Costa Rica \\ *Autor para contacto: denisojo@hotmail.com
}

(Recibido: 04/02/2017; aceptado: 02/05/2017)

\begin{abstract}
We present a geologic map of the Tapantí quadrangle, which is located in the central region of Costa Rica and belongs to the Central Costa Rica Deformed Belt (CCRDB). The CCRDB is a consequence of the interaction of the Cocos Ridge and the Western edge of the Panama microplate. The oldest rocks mapped in this work are Miocene in age and theyvbelongs to Pacacua, Peña Negra and Coris formations, than form the western edge of the Candelaria basin. Three igneous events were distinguished. First, the Miocene volcanic arc, which is represented by the rocks of La Cruz Formation and the clasts of Pacacua Formation. Another period of igneous activity was recorded in Grifo Alto and Doán formations and the Tapantí Intrusive, with an age range of 0.6-0.03 Ma. From a geochemical point of view is remarkable a change between 10 to $6 \mathrm{Ma}$, enrichment of $\mathrm{K}$ and $\mathrm{Si}$ and changes in $\mathrm{U}, \mathrm{Sr}$, Ba and La concentrations. This change corresponds with the Cocos Ridge arriving to the Middle America Trench and it is visible because the Pliocene magmatic arc, the Pliocene intrusive of Tapantí and the nowadays volcanic arc. The structural model suggests the existence of two deformation events, the first occurred during the period of time between Late Miocene and Pliocene and it formed the Folding Zone Orosi-Patarrá, and the second one corresponds to the establishment of CCRDB, from Pliocene to present, which is constituted by left lateral faults bearing ENE and right lateral faults bearing NW.

Keywords: Geologic map, Talamanca, Candelaria basin, volcanic arc, Irazú.

RESUMEN: Se presenta un mapa geológico, escala 1:50 000 del cuadrante Tapantí, el cual se encuentra en la región central de Costa Rica y forma parte del Cinturón Deformado del Centro de Costa Rica (CDCCR), producto de la interacción de la cordillera de Coco y la región W de la microplaca Panamá. Las rocas más antiguas cartografiadas son miocenas y están representadas por las formaciones sedimentarias Pacacua, Peña Negra, San Miguel y Coris, que forman el borde oriental de la cuenca Candelaria. Se distinguieron 3 eventos magmáticos; el arco volcánico Mioceno, representando por la Formación La Cruz y clastos volcánicos de la Formación Pacacua; un nuevo periodo de actividad ígnea entre 6 Ma y 4,2 Ma, representado por las formaciones Grifo Alto, Doán y el Intrusivo de Tapantí y, finalmente, se desarrolla el arco volcánico actual, representado por las formaciones Paraíso y Cervantes, con un rango de edad entre los 0,6 Ma y 0,02 Ma.
\end{abstract}

Sojo, D., Denyer, P., Gazel, E. y Alvarado, G. E. (2017). Geología del cuadrante Tapantí (1:50 000), Costa Rica. Revista Geológica de América Central, 56: 83-116, Doi: 10.15517/rgac.v0i56.29238 
Desde el punto de vista geoquímico, se observa un fuerte cambio entre los 10 y 6 Ma, lo cual se expresa por medio del enriquecimiento de $\mathrm{K}$ y Si, y los cambios en la concentración de U, Sr, Ba, La. Dicho cambio corresponde temporalmente con el arribo de la cordillera de Coco a la Fosa Mesoamericana y es reflejado en la región por medio del arco magmático del Plioceno y el arco volcánico actual. El modelo estructural sugiere la existencia de 2 episodios de deformación, el primero ocurrió durante el periodo comprendido entre el Mioceno Superior y el Plioceno y produjo la Zona de Plegamiento Orosi-Patarrá mientras que el segundo corresponde con la instauración del CDCCR, desde el Plioceno hasta la actualidad, conformado por fallas sinestrales con orientación ENE y dextrales con orientación NW.

Palabras clave: Mapa geológico, Talamanca, cuenca Candelaria, arco volcánico, Irazú.

\section{INTRODUCCIÓN}

Bajo la premisa de que el mapa geológico es el modelo fundamental, sobre el cual se establecen las bases en que se estructuran las diferentes disciplinas geológicas, sean de carácter aplicado o académico, se presenta en este trabajo, el mapa geológico de la hoja topográfica Tapantí (3445 III) del Instituto Geográfico Nacional (Fig. 1). Desde un punto de vista científico, el mapa geológico ofrece las bases para entender la disposición espacial y temporal de las rocas dentro de un modelo tectónico. Valga recalcar, que la importancia del mapa geológico trasciende el conocimiento científico, pues es la base para diversas aplicaciones, tales como la planificación del uso de la tierra, ubicación de infraestructura, búsqueda y localización de fuentes de materiales para la construcción. En definitiva, el desarrollo de país depende, en gran medida del conocimiento de su geología.

El cuadrante Tapantí se encuentra geográficamente situado en la parte central del país (Fig. 1) y corresponde con la estribación NW de la cordillera de Talamanca, incluye la divisoria continental de aguas entre las vertientes caribe y pacífica; donde casi toda la región drena hacia el NE por el río Reventazón y sus afluentes. La topografía es muy abrupta, con alturas que varían desde los $1000 \mathrm{~m}$ hasta los $2840 \mathrm{~m}$.

Desde el punto de vista geológico, esta región representa la interrelación entre la cordillera de Talamanca, con sus unidades volcánicas e intrusivas del Mio-Plioceno, con el vulcanismo Cuaternario de la cordillera volcánica Central. En cuanto a la estratigrafía sedimentaria, se considera que forma el límite oriental de la cuenca
Candelaria del Mioceno, mostrándose únicamente unos pocos afloramientos del Plioceno de la cuenca Limón. Parte de la secuencia sedimentaria se encuentra metamorfisada por la acción de los intrusivos y basculada y plegada como consecuencia de la tectónica. Desde la perspectiva tectónica destaca un fallamiento ENE-WSW de tipo sinestral y un fallamiento NW-SE dextral, producto de una compresión regional N-S.

Con este trabajo se pretende establecer el modelo geológico escala 1:50 000, estratigráfico y estructural, de los $509 \mathrm{~km}^{2}$, que tiene el cuadrante Tapantí. Además de la descripción petrográfica, se utiliza la geoquímica para la caracterización de las unidades volcánicas presentes.

\section{UBICACIÓN GEOTECTÓNICA}

La subducción de la placa del Coco bajo la Caribe es el rasgo geotectónico con mayor influencia en todo el territorio costarricense, lo que es lo que es impulsado por los centros de dispersión formados entre la placa del Coco con las placas del Pacífico Oriental y Nazca (Fig. 2). La corteza oceánica que se subduce frente a Costa Rica tiene una firma geoquímica contaminada por el punto caliente de Galápagos, lo que generó una segmentación en la subducción, con una losa asísmica y deshidratada (Lücke y Arroyo, 2015) en el SE de Costa Rica (Fig. 1).

La corteza bajo el territorio costarricense se considera anómala con respecto a un arco de islas normal (p.e. Vogel et al., 2004, Vogel et al. 2007), por lo que recientemente Gazel et al. (2015) proponen que tal anomalía corresponde 


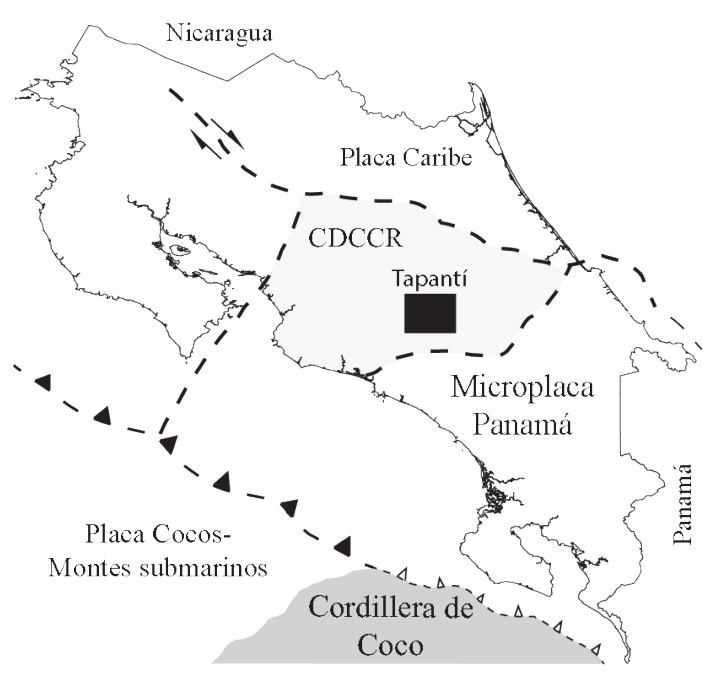

Fig. 1: Ubicación del cuadrante Tapantí en un contexto geotectónico. Los triángulos en negro indican la dirección de inclinación de la zona de subducción a lo largo de la fosa Mesoamericana. Los triángulos en blanco muestran la zona de subducción más superficial. CDCCR (Cinturón Deformado del Centro de Costa Rica).

con un proceso de continentalización cortical derivado de la interacción entre un arco de islas y las trazas de un punto caliente (cordillera del Coco).

Finalmente, la región de Tapantí se encuentra en lo que Montero (2003) define como el Cinturón Deformado del Centro de Costa Rica (CDCCR, Fig. 1), el cual se considera como el borde de la microplaca Panamá.

\section{ANTECEDENTES}

Entre las primeras referencias de las litologías aflorantes en el cuadrante Tapantí se puede mencionar a Weyl (1954), que describe por primea vez los intrusivos aflorantes en las cercanías de Santa María de Dota, Dengo (1962) menciona las rocas del Grupo Aguacate. Escalante (1966) denomina a la Formación Doán. Castillo (1969) describe las Formaciones Pacacua y Coris, mencionando algunas localidades dentro del cuadrante; Valverde (1989) realiza el cartografiado de un sector al SE del cuadrante. Berrangé y Wittaker (1977) realizan el primer estudio que abarca todo

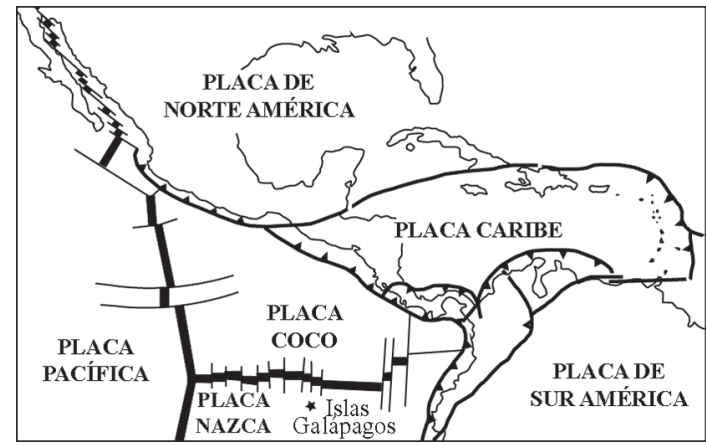

Fig. 2: Contexto geotectónico regional. Disposición espacial entre las 6 placas tectónicas que interaccionan en la región Se muestra con línea gruesa los márgenes divergentes, con triángulos las zonas de subducción y con línea continua los movimientos de rumbo.

el cuadrante Tapantí, trabajo que consistió de una fotointerpretación con algunos puntos de comprobación en el campo.

En los últimos años destacan algunos informes internos del ICE (Instituto Costarricense de Electricidad), una Tesis de Licenciatura como el trabajo presentado por Aguilar (1982) quien realiza el cartografiado del sector occidental. Alvarado y Pérez (1998) discuten acerca de la Formación Doán. Badilla, Linkimer y Zúñiga (1999) realizan una Campaña Geológica al NW del área. Alvarado y Gans (2012) realizan una compilación de datos radiométricos existentes. Sojo (2015) realiza un modelo geológico para el cuadrante Tapantí, como parte de su Tesis de Licenciatura.

Dentro de los trabajos aledaños a la hoja Tapantí, se pueden citar a Denyer y Alvarado (2007), Denyer y Arias (1991), Fernández (1987) y Krushensky (1972), así como publicaciones de síntesis sobre las características químicas, como Gazel et al., 2009, Gazel et al., 2011. La compilación de edades radiométricas de Alvarado y Gans (2012) fue utilizada como referencia para establecer el contexto geológico regional del cuadrante Tapantí. Dicha información ha sido visualizada desde el punto de vista de evolución tectónica de la región, lo cual engloba procesos como la evolución de arcos de islas, "continentalización" de corteza oceánica y evolución de cuencas sedimentarias. 


\section{MÉTODOS}

Se realizaron más de 100 visitas al campo, con más de 300 afloramientos levantados (Fig. $3)$. De las muestras recolectadas se seleccionaron para hacer los análisis petrográficos, geoquímicos y paleontológicos. La información geológica se compiló en un SIG (Sistema de Información Geográfica), el sistema de coordenadas empleado fue el Lambert Norte y se utilizaron las fotografías aéreas y topografía del proyecto TERRA 1997 y MED (Modelo de elevación digital).

Con respecto a la geoquímica, se trabajó con 18 muestras de rocas, las cuales se analizaron petrográficamente para descartar muestras alteradas. Posteriormente, fueron cribadas y los granos o gravas obtenidos fueron lavados con agua desionizada en una pila ultrasónica. Con un microscopio estereoscópico se descartaron las gravas con indicios de alteración. Se tomaron aproximadamente $25 \mathrm{mg}$ de grava de cada muestra y se pulverizó usando moldes de porcelana. El polvo obtenido fue fundido y combinado con tetraborato de Litio (Li2B4O7) y vertido en discos de vidrio. Finalmente, se analizaron los discos para determinar concentraciones de elementos mayores y traza por medio de Fluorescencia de Rayos X (FRX) en un Bruker S4 Pioner, y por medio de un espectrómetro de masas (LA-ICP-MS) en un Micromass Platform ICP-MS, respectivamente.

\section{ESTRATIGRAFÍA}

La columna estratigráfica sedimentaria e ígnea se muestra en la Figura 4. Las unidades son referidas al mapa geológico derivado del presente trabajo, donde se detalla a escala 1:50 000 la distribución espacial de las mismas y sus relaciones de campo, por lo que es un instrumento fundamental a la hora de leer este trabajo. A continuación, se hará la descripción de unidades, tanto sedimentarias como ígneas, así como la unidad metamórfica. Dicha descripción se hace de la más antigua a la más joven, respetando las normas estratigráficas oficiales de la International Union of Geological Sciences (Salvador, 1994). Por lo tanto, de cada unidad se describen sus características fundamentales: estratotipo, descripción, aspectos regionales, edad, correlación con otras unidades y otras áreas, génesis y antecedentes.

\section{Formación Pacacua}

Corresponde con una unidad geológica que se depositó en un ambiente marino de plataforma con evidente contribución volcánica.

\section{Estratotipo}

Castillo (1969) define por primera vez a esta formación y menciona como localidad tipo al flanco $\mathrm{N}$ del cerro Pacacua (cuadrante Abra, coordenada aprox. 514000-210000). En el cuadrante Tapantí algunos afloramientos destacables, el primero se observa en el camino que va de Puente Negro a San Chiri, donde aflora la parte media de la secuencia y el segundo en el poblado de Navarro, donde se observan estratos correspondientes a la parte superior de la secuencia (551077-199948, Fig. 5 A).

\section{Descripción}

Romanes (1912) menciona "tobas fosilíferas" haciendo referencia a las rocas correspondientes a esta formación. Posteriormente, numerosos autores describen a esta formación, tales como Dengo y Chaverri (1944), Rivier (1978), Alvarado, M.E. (1982), Castillo (1969), Berrangé y Wittaker (1977), y finalmente Denyer y Arias (1991), quienes redefinen a esta unidad, excluyendo las lutitas y areniscas finas de la Formación Peña Negra.

En el área de estudio se presenta principalmente como volcarenitas y brechas volcaniclásticas con ocasionales intercalaciones de coladas de lava, Las volcarenitas presentan tonalidades grises y moradas, con una granulometría que varía de arenas medias a conglomerados brechosos, con clastos de hasta $25 \mathrm{~cm}$ de diámetro, la estratificación es decimétrica a masiva. Los clastos son mayoritariamente angulosos y están compuestos principalmente por fragmentos de rocas volcáni- 


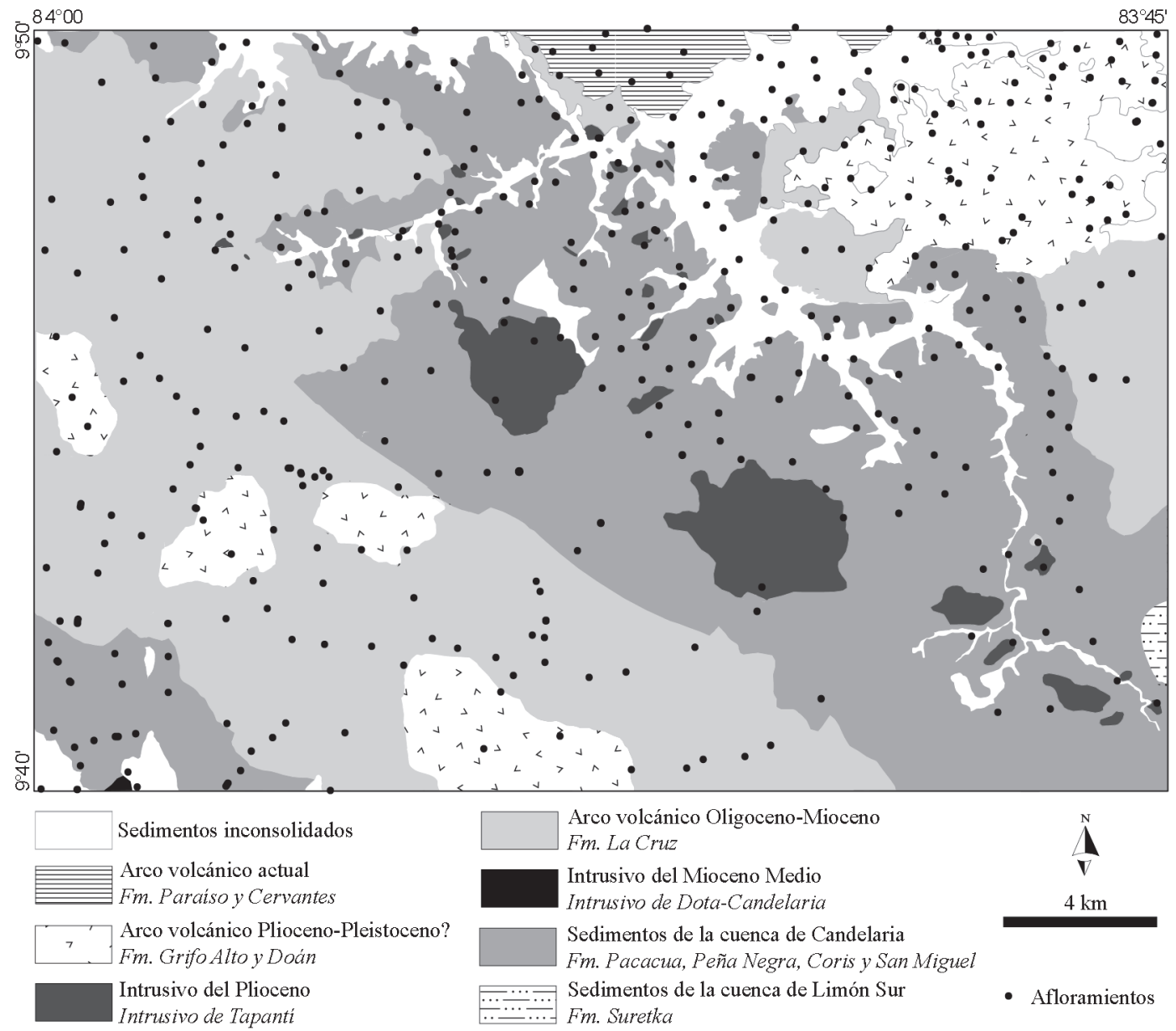

Fig. 3: Distribución de afloramientos observados, ubicados dentro de 8 macro-unidades del cuadrante Tapantí.

cas en las facies de granulometría gruesa y en las arenas medias por material variado entre restos de moluscos, cristales de plagioclasa idiomórficos y cuarzo, además presenta estructuras de carga (laminación convoluta y estructuras en flama)

Las brechas se presentan hacia el techo de la secuencia y se correlacionan con el miembro Brechas Verdes Coyolar, definido por Denyer y Arias (1991), debido a la similitud en las descripciones, así como su ubicación estratigráfica. Generalmente presentan tonalidades verdes, granulometría media, clastos de hasta $2 \mathrm{~cm}$ de largo, amígdalas rellenas con variedades amorfas de cuarzo, litoclástos andesíticos, cristales de piroxeno y una matriz verdosa, la cual ha sido sustituida por minerales secundarios como epidota, clorita y glauconita.
En general, se determina la presencia de brechas, grauvacas, arenas y coladas de lava, lo anterior evidencia la relación entre el vulcanismo de la época y la sedimentación de algunas facies de la formación. Los datos petrográficos de 16 láminas delgadas indican el domino de componentes alóctonos, mayoritariamente clastos angulosos de rocas volcánicas, cristales de plagioclasa, cuarzo, glauconita, entre otros.

Las coladas de lava se observaron en algunos afloramientos aislados, como por ejemplo en los cimientos del puente que comunica al poblado de la Alegría con Orosi.

En la región central del país se estima un espesor máximo de 1300 m (Denyer y Arias, 1991), mientras que en el área de estudio se logró estimar un espesor cercano a los $500 \mathrm{~m}$. 


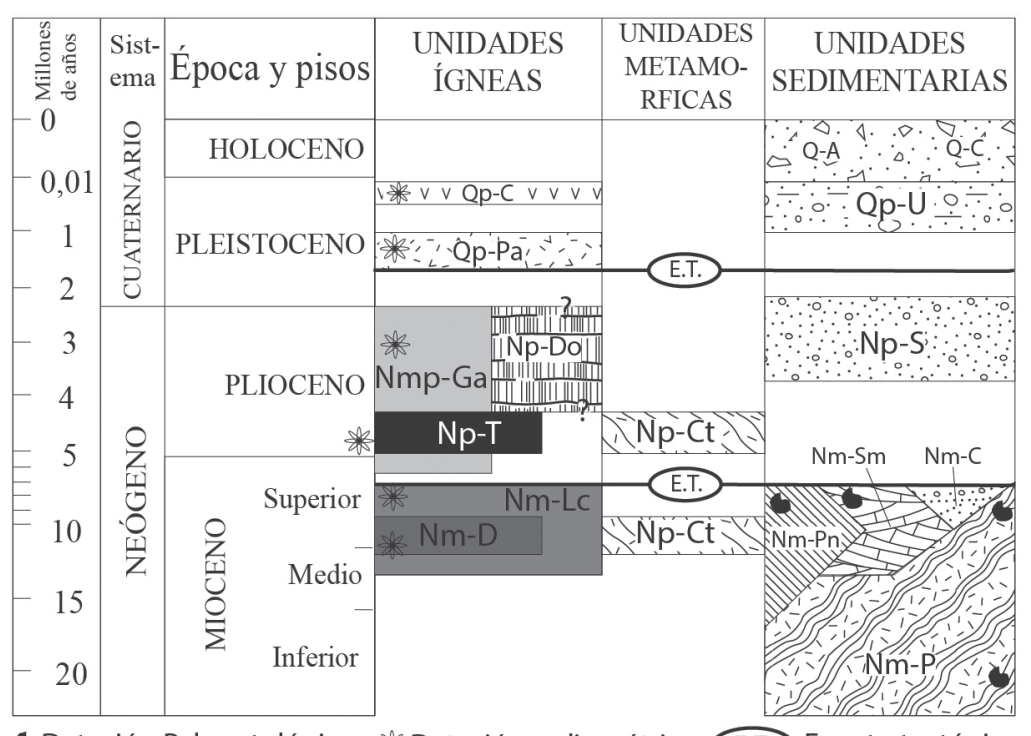

Datación Paleontológica * Datación radiométrica E.T. Evento tectónico

\section{Unidades Sedimentarias}

Aluvión

Q-C.]. Depósito Coluvial

QO- T-U. Formación Ujarrás

Np-S $\begin{array}{ll}\text { Formación Suretka } \\ \text { Conglomerado }\end{array}$

$\because \mathrm{Nm}-\mathrm{C}$ Frenisca cuarzosa

$\frac{1}{\mathrm{Nm}-\mathrm{Sm}}$ Formación San Miguel

Caliza bioclástica, arenizca calcárea

Nm-Pny Formación Peña Negra
Lutita, arenisca calcárea

NḾm-Pi Formación Pacacua

Mr Arenisca, brecha, andesita

\section{Unidades Ígneas}

\section{Unidades Metamórficas}

Np-Ct Aureola de metamorfismo

Fig. 4: Columna estratigráfica del cuadrante Tapantí. 

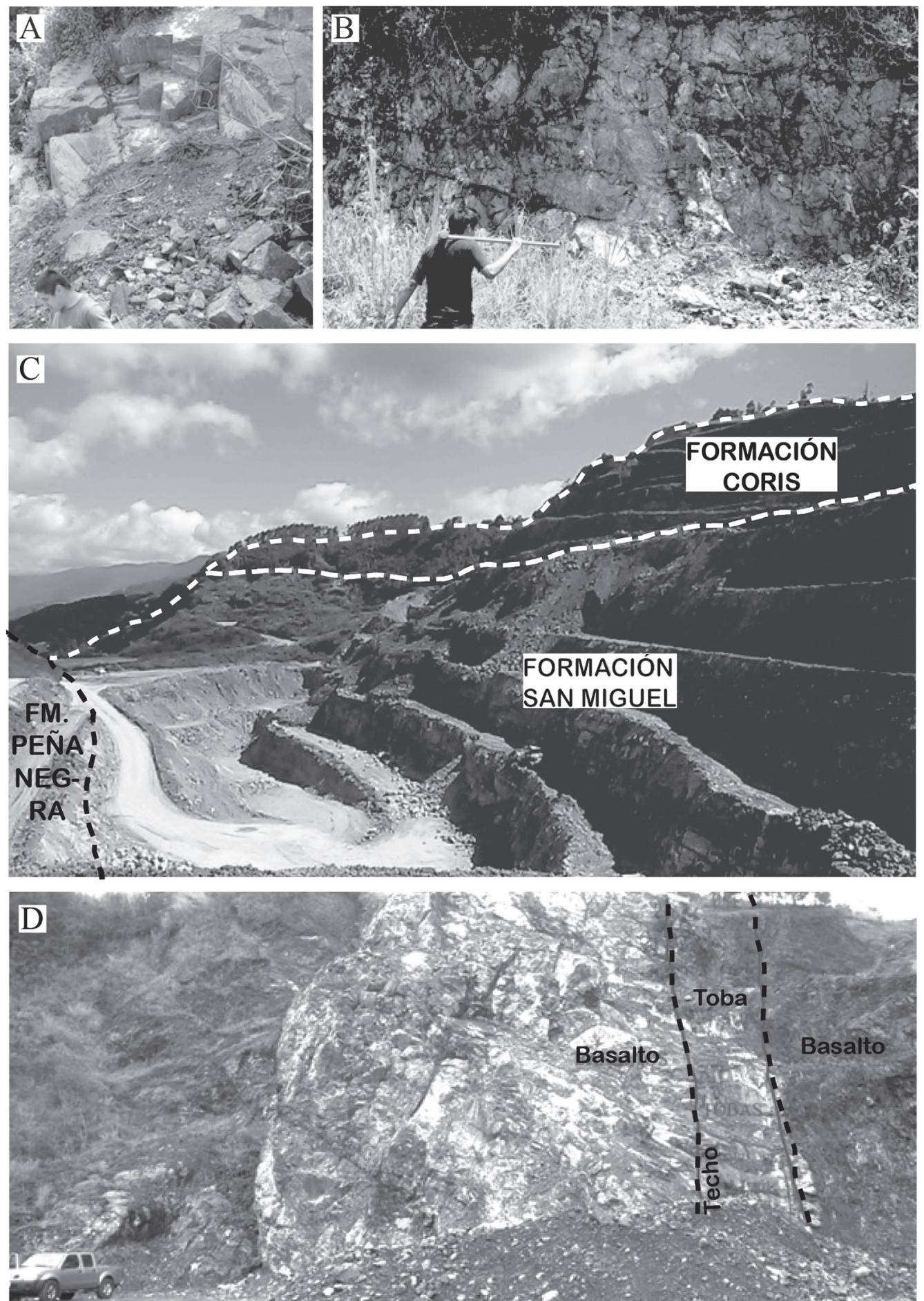

Fig. 5: A. Afloramiento de la formación Pacacua en el río Navarro. B. Afloramiento de la Formación Peña Negra, Embalse el Llano. C. Afloramiento de las formaciones Peña Negra, San Miguel y Coris, tajo La Chilena. D. Afloramiento de la Formación La Cruz, tajo El Volcancito. 


\section{Edad}

Mioceno Inferior a Mioceno Medio con base en sus relaciones de campo (Denyer y Arias, 1991).

\section{Paleontología-icnología}

Valverde (1989) describe radiolarios (spumellaria), mientras que en el desarrollo de este trabajo se han observado trazas fósiles zoophycus y fragmentos de moluscos. Las tobas muestran abundancia de materia orgánica.

\section{Correlación con otras unidades y áreas}

Según Rivier y Calvo (1988) la Formación Pacacua sobreyace discordantemente a la Formación Parritilla, la cual presenta una edad Eoceno. Sin embargo, Denyer y Arias (1991) indican que la secuencia de la Cuenca Candelaria es concordante y se inicia con las formaciones Parritilla y Caraigres, que subyacen a la Formación Pacacua. Fischer y Franco (1979), Alvarado (1982) y Rivier (1982) consideran que su contacto con las formaciones San Miguel y Coris es lateral, mientas que Castillo (1969) afirma que Pacacua es sobreyacida por la Formación San Miguel. Denyer y Arias (1991) definen la Formación Peña Negra, que está sobreyaciendo a Pacacua y que, San Miguel y Coris se encuentran sobreyaciendo a Peña Negra. Alvarado y Gans (2012) correlacionan a Pacacua con la unidad Mata de Limón (19,4 - 10,9 Ma).

En el área de estudio se presenta como la unidad de mayor antigüedad, cuya parte superior corresponde con el miembro Brechas Verdes en contacto gradual, sobreyacido por la Formación Peña Negra.

\section{Génesis}

Alvarado, M.E. (1982) fue el primer autor en aplicar un modelo de facies para la Formación Pacacua, basado en criterios sedimentológicos para las rocas aflorantes en el Valle Central. Según sus conclusiones, el ambiente de depositación de esta litología es sublitoral, somero, y la sedimentación se dio en un delta o fandelta. Lo propuesta anterior se ve reforzada en el área de estudio por el hecho de que es notable que la sedimentación fue cercana a la línea de costa, lo que se refleja en la granulometría de las volcarenitas, la abundancia de materia orgánica en las tobas, la presencia de brechas (gradación negativa), y coladas de lava intercaladas con los sedimentos, además de la presencia de peperitas (Soto y Alvarado, 2012).

\section{Formación Peña Negra}

Dóndoli y Chaves (1968) mencionan por primera vez rocas de tonalidades oscuras, que deben corresponder con esta unidad y utilizan el nombre de Formación Piedras Negras. Castillo (1969) las cartografía como Formación Térraba. Posteriormente, Denyer y Arias (1991) definen formalmente a esta unidad.

\section{Estratotipo}

Denyer y Arias (1991) definen esta unidad e indican como la localidad tipo un sitio conocido como Peña Negra, en el cuadrante Candelaria (501000-197000). La dividen en 3 unidades diferenciables; a) inferior, que corresponde con areniscas medias y finas, con tonalidades pardas, b) media, que corresponde con lutitas y areniscas finas, 
con tonalidades oscuras y abundancia de pirita, c) la superior que está representada por areniscas de grano medio a grueso, con abundante influencia volcánica. En el área de estudio se han logrado identificar las unidades media y superior.

La unidad media presenta lutitas y areniscas finas, expuesta en buenos afloramientos en el camino que conduce de la planta de generación eléctrica en Río Macho hacia el embalse El Llano; dicho camino muestra varios afloramientos especialmente en la coordenada 551490-195610 (Fig. 5 B). La unidad superior puede ser observada en el Tajo La Chilena (548100-200900, Fig. 5 C), y en Agua Caliente de Cartago, donde se observa con bastante claridad, en contacto con la unidad superior con las calizas de la Formación San Miguel.

\section{Descripción}

En el cuadrante Tapantí la Formación Peña Negra presenta dos de las unidades descritas por Denyer y Arias (1991). La unidad media aflora en las cercanías del valle de Orosi y Agua Caliente de Cartago; en general se presenta como intercalaciones de lutitas y areniscas finas. Las lutitas presentan tonalidades oscuras, abundancia de pirita, moldes de moluscos y esporádicamente algunos clastos andesíticos. Se observaron moldes de moluscos en el sector de Calle Lajas y cerca del embalse El Llano. En Calle Lajas también destaca la presencia de concreciones.

Las areniscas finas se presentan hacia la parte superior, sobre las lutitas, lo cual denota la presencia de gradación negativa en la Formación Peña Negra. La estratificación de esta unidad es decimétrica y se observa laminación convoluta y estratos acuñados.
Petrográficamente, las areniscas muestran clastos subredondeados a angulosos y cemento es calcáreo. Es frecuente la presencia de plagioclasa hipidiomórfica, así como la presencia de minerales opacos.

Según las observaciones de campo y los resultados del cartografiado geológico, el espesor mínimo para esta formación es de $450 \mathrm{~m}$.

\section{Edad}

Una muestra tomada en el área de estudio (549140-194859) y estudiada por la paleontóloga T. Aguilar presentó un ejemplar de Chlamys (Aequipecten) aff. levicostatus, el cual se correlaciona con una edad de Mioceno Medio a Mioceno Superior.

\section{Paleontología-icnología}

Por medio de la observación de láminas delgadas, se identificaron varios foraminíferos y varios fragmentos de moluscos. En muestras de mano es posible observar moldes de bivalvos, y concreciones calcáreas. Denyer y Arias (1991) detallan la presencia de Praeorbulina glomerosa, Orbulina cf. universa, Bulimina sp. y Globorotaria sp.

\section{Correlación con otras unidades y áreas}

Según Denyer y Arias (1991) se encuentra sobreyaciendo a la Formación Pacacua o al miembro Brechas Verdes Coyolar por medio de un contacto transicional y se encuentra en contacto lateral con las formaciones Coris y San Miguel. 
En el tajo La Chilena y el camino que comunica a Muñeco con Navarro, se concluye que la Formación Peña Negra grada lateralmente hacia facies someras de las formaciones San Miguel y Coris (Fig. 5C). En las cercanías del embalse el Llano y en el río Sombrero y Naranjo se observa a la unidad superior de la Formación Peña Negra en contacto con las areniscas cuarzosas de la Formación Coris.

\section{Génesis}

Según el modelo propuesto por Alvarado (1982), se depositó en condiciones anóxicas, sin influencia de mareas, y con influencia de varios episodios volcánicos, lo cual coincide con lo expuesto por Denyer y Arias (1991), donde se interpreta que la sedimentación se dio en la plataforma interna.

En varios de los cortes levantados en el presente trabajo, la unidad media de esta formación responde a un periodo de calma tectónica, con influencia de al menos dos eventos volcánicos. Lo anterior se evidencia por el aumento de granulometría en algunos estratos en contraste con las lutitas). Finalmente, la unidad superior representa un periodo de mayor actividad volcánica, reflejado en el cambio de granulometría y tonalidad es con respecto a la unidad media, además la presencia de cristales idiomórficos a hipidiomórficos de plagioclasa descritos por Denyer y Arias (1991).

\section{Formación San Miguel}

Es una unidad geológica constituida por calizas, históricamente se ha utilizado como una de las materias primas para la producción de cemento.

\section{Estratotipo}

Según Denyer y Arias (1991) los mejores afloramientos de esta Formación se presentan en el anticlinal de Patarrá, cuadrante Abra, lugar el cual proponen como hipoestratotipo. En el cuadrante Tapantí se le puede observar en la base al techo en el Tajo La Chilena (548100-200900, Fig. 5 C).

\section{Descripción}

Fernández y Madrigal (1960) utilizan por primera vez el nombre de caliza de San Miguel para referirse a afloramientos de las calizas localizados en el anticlinal de Patarrá, en el cuadrante Abra. Umaña y Escalante (1962) señalan que en el cuadrante Tapantí la formación está compuesta por areniscas, calizas y conglomerados. Según Carballo (1978) está compuesta por calizas bioclásticas, calizas cristalinas y calizas nodulares, con la ocurrencia esporádica de estratos de volcarenitas y calizas guijarrosas. En el presente trabajo los afloramientos visitados indican que las calizas son de tipo cristalino, compuestas en más de un $50 \%$ de material aloquímico, y con la poca presencia de fósiles. Dichas calizas presentan tonalidad pardo claro, buena estratificación, con estratos no mayores a $1 \mathrm{~m}$ de espesor, el material interestrato ocasionalmente se compone por lutitas pardas y areniscas finas y se encuentra alterado.

Los estratos de conglomerados, descritos por Umaña y Escalante (1962), se lograron identificar en tajo La Chilena y se identificaron 2 estratos, el primero corresponde con el techo de la unidad superior de la Formación Peña Negra. mientras que, el segundo estrato se identifica hacia la parte media de la Formación San Miguel. Dichos conglomerados están compuestos por litoclástos volcánicos andesíticos, la mayoría subredondeados, con tamaños no mayores a los $10 \mathrm{~mm}$ de diámetro, cristales de plagioclasa, vidrio, fragmentos de fósiles y una matriz arenosa.

La Formación San Miguel, en el cuadrante Tapantí, presenta un dominio de materiales autóctonos (caliza cristalina), lo que junto con el aumento de espesor de esta unidad en el área de estudio (200 m en el tajo La Chilena) indica que la geometría de esta formación es acuñada, con presencia de materiales que sugieren mayor profundidad de 
depositación con respecto a otras localidades. Por ejemplo, 'Carballo (1978) describe la presencia de macrofauna como componente principal de estas rocas. Lo anterior puede ser relacionado con las características geométricas de la cuenca, la cual sugiere mayor espesor hacia el cuadrante Tapantí.

En el cuadrante Tapantí, esta formación representa una franja que se extiende unos $10 \mathrm{~km}$, desde el tajo La Chilena hacia el S, que buza hacia el SW-W y notablemente se adelgaza hacia el S, hasta que desaparece acuñada.

\section{Edad}

Carballo y Fischer (1978) determinan una edad de Mioceno Inferior - Mioceno Medio basado en criterios paleontológicos.

\section{Paleontología}

En los afloramientos visitados se determinó la presencia de al menos los siguientes fósiles: Argopecten, Aequipecten y Flabellipecten.

\section{Correlación con otras unidades y áreas}

Según Carballo (1978) esta formación se encuentra sobreyaciendo a la Formación Térraba (ahora Peña Negra), y subyaciendo a la Formación Coris. Denyer y Arias (1991) sugieren que sus contactos son laterales con las formaciones Peña Negra y Coris, lo cual coincide con el modelo propuesto por Alvarado (1982) y Fisher y Franco (1979).

\section{Génesis}

Carballo (1978) concluye que el ambiente fue de baja salinidad, temperatura tropical, lejos de tierra firme, turbulento, con una taza de sedimentación rápida que se interrumpía ocasionalmente. El presente trabajo concuerda con lo anterior, y además se señala que durante la sedimentación de las calizas se dieron varias interrupciones, las cuales alteraron el sistema, lo que se refleja en los estratos de conglomerados y lutitas.

\section{Formación Coris}

Esta unidad geológica se caracteriza por su alto contenido de cuarzo, por lo que se le utiliza para la fabricación de vidrio, como piedra para afilar o como material para la realización de esculturas.

\section{Estratotipo}

Castillo (1969) define el Alto de Coris como localidad tipo de esta formación (cuadrante Abra, 536000 - 207000). Fischer y Franco (1979) proponen el sector que se extiende de Río Azul a San Diego de Tres Ríos, ya que este camino muestra uno de los perfiles más completos de esta formación. El presente trabajo señala que en el cuadrante Tapantí existen buenos afloramientos en el camino que va del hotel Río Perlas hacia el poblado de Muñeco, donde se exponen varios cortes de esta unidad. También aflora en las cercanías del embalse El Llano, tajo La Chilena (Fig. 5 C) y los poblados de Palo Verde y La Estrella.

\section{Descripción}

Castillo (1969) define litológicamente a la Formación Coris como capas espesas de areniscas cuarzosas con intercalación de algunas capas delgadas de lutitas. Denyer y Arias (1991) presentan una descripción similar, agregando además la presencia de algunas capas de conglomerado y lignito. Fisher y Franco (1979) presentan un trabajo específico de esta formación, realizado entre los cuadrantes Tapantí, Istarú y Abra.

En los cortes levantados en el presente trabajo se logró determinar la presencia de dos de las tres facies mencionadas. Las facies marinas 
son observables en el cerro Jucosal (545500200250) y en la localidad tipo propuesta para el cuadrante Tapantí (tajo La Chilena) en ambos casos los afloramientos se encuentran en las cercanías del contacto con la Formación San Miguel. Litológicamente corresponden con areniscas cuarzosas, con presencia de laminación cruzada, alta madurez textural, compuesta por granos de cuarzo subredondeados a redondeados, y la presencia esporádica de feldespatos retrabajados. Presenta tonalidades blancas cuando no está meteorizada y tonos pardos cuando se encuentra afectada por la meteorización.

En las cercanías del embalse El Llano, se observa una capa de lignito de 2,3 $\mathrm{m}$ de espesor, intercalada con las lutitas y areniscas, lo cual se interpreta como la facies parálica. Los estratos de arenisca y lutita muestran tonalidades pardas, selección regular: y microscópicamente se nota la presencia de cemento silíceo y baja porosidad. También se lograron identificar laminación cruzada y ripples en las facies intermedias

La Formación Coris tiene forma tabular, un espesor mínimo para el área de estudio cercano a los $200 \mathrm{~m}$, y se extiende en un área de $34 \mathrm{~km}^{2}$ en el área del cuadrante Tapantí.

\section{Edad}

Basados en criterios paleontológicos, Fischer y Franco (1979) le asignan una edad de Mioceno Medio a Mioceno Superior.

\section{Paleontología-icnología}

Fischer y Franco (1979) reportan la presencia de bivalvos y gasterópodos, icnofósiles y lignito. Denyer y Arias (1991) reportan además la presencia de foraminíferos. En el presente trabajo se logró determinar la presencia de ignofósiles y lignitos en las facies terrestres.

\section{Correlación con otras unidades y áreas}

Franco (1978) señala que su contacto superior se da de manera concordante con rocas volcánicas, lo cual es reafirmado por Denyer y Arias (1991). Fischer y Franco (1978) y Carballo (1978) determinan que su contacto inferior se da de manera concordante con la Formación San Miguel, En la parte $\mathrm{N}$ del área de estudio se le observa sobreyaciendo a la Formación San Miguel, mientras que hacia la parte central del cuadrante Tapantí se le infiere un contacto con la Formación Peña Negra. El contacto superior puede ser observado en el camino que comunica al poblado de Muñeco con Lourdes de Agua Caliente, donde se tiene a la Formación La Cruz cubriendo a las areniscas cuarzosas sobreyaciendo a Coris.

\section{Génesis}

Fischer y Franco (1978) determinaron la presencia de 3 facies: marina sublitoral, aguas someras y terrestre. Por otra parte, dichos autores consideran que el material de aporte proviene de una fuente volcánica, con aporte de rocas ricas en cuarzo (probablemente ignimbritas). Sin embargo, los detalles de dicho vulcanismo son escazas.

\section{Intrusivo de Dota-Candelaria}

El cuadrante Tapantí representa parte de las últimas estribaciones de la cordillera de Talamanca y donde se presenta una pequeña exposición en el SW del cuadrante.

\section{Estratotipo}

Weyl (1962) reporta por primera vez cuerpos intrusivos en las cercanías de la comunidad de Dota, en el límite entre las cuadrantes Tapantí 
y Vueltas. Denyer y Arias (1991) realizan el cartografiado de parte de este cuerpo intrusivo en el cuadrante Caraigres, en la localidad de Monterrey. No se ha descrito una localidad tipo como tal, pero debería estar en la cordillera de Talamanca, donde el intrusivo tiene su mayor expresión.

\section{Descripción}

Gabb (1874) reporta la presencia de rocas intrusivas en la Cordillera de Talamanca, posteriormente numerosos autores han mencionado dichas rocas. Kussmaul (1987) describe brevemente a esta litología y determina que se trata de gabros hasta granodioritas. Denyer y Arias (1991) describen un cuerpo intrusivo tabular, concordante con la secuencia sedimentaria, con $6 \mathrm{~km}$ de longitud y $500 \mathrm{~m}$ de ancho, el cual correlacionan con el Intrusivo de Escazú, mientras que MacMillan, Gans y Alvarado (2004) demostraron que existe una diferencia de edad al menos 3 Ma entre ambas litologías.

La petrografía hecha en el presente trabajo clasifica estas rocas como granodioritas con hornbleda y biotita y monzogabros. Según los análisis químicos realizados (2 muestras), se tiene que las rocas se clasifican como grabros y monzodioritas.

\section{Edad}

Para este cuerpo intrusivo Bergoeing (1982) reporta una edad de 9,13 Ma obtenida por el método $\mathrm{K} / \mathrm{Ar}$, mientras que MacMillan, Gans y Alvarado (2004) reportan edades de 10,6 a 8,68 Ma (Ar/Ar).

\section{Correlación con otras unidades y áreas}

Se encuentra intruyendo la secuencia sedimentaria, pero con una tendencia semi-paralela a la estratificación.

\section{Génesis}

Alvarado y Gans (2012) determinan que se trata de un pulso magmático que se dio en un periodo de tiempo claramente establecido entre los 12,4 y los 7,8 Ma y que se encuentra relacionado con la evolución magmática de la cordillera de Talamanca.

\section{Formación La Cruz}

Esta unidad geológica representa la cobertura volcánica concordante de la cuenca Candelaria y que consecuentemente se deformó de la misma manera que la secuencia sedimentaria (Denyer y Arias, 1991).

\section{Estratotipo}

Denyer y Arias (1991) definen por primera vez a esta formación y ubican su localidad tipo en el poblado de La Cruz, en el cuadrante Candelaria. El presente trabajo determinó que la mejor localidad para observar esta litología dentro del cuadrante Tapantí es en el tajo El Volcancito (541650-201080, Fig. 5 D), a 1 km S de San Isidro de Cartago, junto a la Carretera Interamericana.

Otras localidades en el cuadrante Tapantí donde se puede observar la litología correspondiente a la Formación La Cruz es en el tajo Ventolera, en las cercanías del Empalme, tajo Don Luis, en las cercanías de Paraíso, Parque Nacional Tapantí y varios afloramientos aislados en la sobre la Carretera Interamericana.

\section{Descripción}

Denyer y Arias (1991) la definen como basaltos, andesitas y tobas. Fácilmente reconocibles por la presencia de amígdalas rellenas, vetillas 
rellenas con calcita, tobas color rojizo y que generalmente presenta evidencias de basculamiento.

En el presente trabajo se utilizaron los criterios anteriores para el reconocimiento de esta formación. Además, se encontraron pequeñas mineralizaciones de malaquita (principalmente en el tajo Cóncavas), así como la intercalación de los basaltos y las tobas. El afloramiento en el tajo El Volcancito se considera clave para comprender las características de estas litologías, pues se observa una secuencia de basaltos, tobas y brechas por cizalle, donde es destacable la presencia de peperitas en el contacto vertical entre basaltos y tobas, obteniéndose un criterio de ambiente polaridad, pues marcan el piso de la colada. Es importante señalar que la presencia de peperitas en localidades cercanas ha sido también reportada por Soto y Alvarado (2012).

A nivel macroscópico, los basaltos sanos muestran tonalidades oscuras, fenocristales de plagioclasa y esporádicos olivinos; cuando se encuentran meteorizados toman una textura brechosa, mostrando seudoclastos subredondeados, tonalidades verduzcas producto de la fuerte alteración y son fácilmente deleznables. Las tobas por lo general exhiben tonalidades rojizas, cristales de plagioclasa, clastos lávicos y una matriz fina.

Petrográficamente corresponde con basaltos, andesitas basálticas, y andesitas. Por lo general las lavas presentan amígdalas rellenas con minerales secundarios (calcita, zeolitas, calcedonia y clorita), olivinos alterados a clorita e Iddingsita y fantasmas de olivino, cristales hipidiomórficos de plagioclasa, un solo tipo de piroxeno (clinopiroxeno), y alteración a epidota, clorita y calcita. Las brechas analizadas corresponden con un avanzado estado de cizalle, donde la matriz y la mayoría de fenocristales han sido reemplazados por minerales de alteración (epidota, clorita, calcita) y la mayoría de grietas u oquedades han sido rellenadas con variedades amorfas de cuarzo, zeolitas y calcita.
En el área de estudio se le determinó un espesor de $650 \mathrm{~m}$ basado en perfiles, mientras que Denyer y Arias (1991) determinaron un espesor de 1500 m en el área de cerro La Cruz.

\section{Edad}

Según Denyer y Arias (1991) esta formación presenta una edad de Mioceno Superior terminal basado en criterios estratigráficos y en la datación (K/Ar) suministrada por Bellon y Tournon (1978) de 8,3 Ma. En las cercanías del área de estudio (cuadrante Vueltas), Gazel et al. (2009) reportan edades $\mathrm{Ar} / \mathrm{Ar}$ de hasta 14,1 Ma, mientras que MacMillan, Gans y Alvarado (2004) reportan para localidades cercanas edades de 10,5 Ma. Por su parte, Alvarado y Gans (2012) le asignan un rango de edad de 19,9 - 10,5 Ma.

\section{Correlación con otras unidades y áreas}

Fischer y Franco (1978) y Carballo (1978) reportan un contacto concordante entre la Formación Coris y rocas volcánicas sobreyacientes. Denyer y Arias (1991) coinciden con lo anterior y definen que la Formación La Cruz se encuentra sobreyaciendo de manera concordante a las formaciones sedimentarias. Las formaciones Grifo Alto, Doán y Paraíso sobreyacen a la Formación La Cruz por medio de una discordancia angular.

\section{Génesis}

Denyer y Arias (1991) asocian a esta Formación con una serie de rocas volcánicas posiblemente extruidas por medio de fisuras eruptivas, basculadas, al igual que la secuencia sedimentaria subyacente, determinando que la depositación de 
dichas rocas volcánicas fue interrumpida por un evento tectónico asociado al arribo de la cordillera de Coco, cerca del límite Mioceno-Plioceno.

Autores como MacMillan, Gans y Alvarado (2004), Gazel et al. (2006) y Alvarado y Gans (2012) aportan nuevos datos acerca de las características genética. En general, dichos autores obtienen una serie de datos geocronológicos y geoquímicos, con el objetivo de enmarcar las rocas de esta formación dentro del contexto de evolución de arcos de islas y la influencia de eventos tectónicos como lo es el arribo de la cordillera de Coco. El consenso entre dichos autores es la existencia de un arco volcánico entre el OligocenoMioceno (Frente Protovolcánico), el cual presenta una tendencia toleítica a calcoalcalina.

El presente trabajo asocia a las rocas de la Formación La Cruz con una fase final, toleítica, de dicho arco volcánico (19 - 8 Ma). Dicha fase volcánica puede ser considerada como volcanísmo preintrusivo (con respecto al Intrusivo de Dota-Candelaria, 8,9 Ma), y simultáneo a la depositación de la secuencia sedimentaria subyaciente, la cual presenta varias capas o eventos volcánicos dentro de las facies sedimentarias.

\section{Intrusivo de Tapantí}

Corresponde con 2 cuerpos aflorantes de unos $3 \mathrm{~km}$ de diámetro y varias pequeñas intrusiones que cortaron la secuencia sedimentaria.

\section{Estratotipo}

Durante el proceso de ejecución del Proyecto Hidroeléctrico Río Macho, a finales de los cincuentas y principio de los sesentas, se realizan los primeros trabajos geológicos en el área al SE del cuadrante Tapantí. Dichos trabajos son presentados por Umaña (1964) y es donde por primera vez se evidencia la existencia de cuerpos intrusivos en el área de estudio.

Dadas las condiciones actuales de los afloramientos y debido a que el acceso al P.H. Río Macho es restringido, se propone como estratotipo al afloramiento situado en las coordenadas 553095-194920, al lado del camino que conduce hacia el embalse El Llano.

\section{Descripción}

Umaña (1964), Berrangé y Wittaker (1977), Madrigal et al. (1987) y Sanabria (2014), lo describen como una serie de rocas que varían desde gabros a granodioritas. Además, los autores concuerdan en que se encuentra cortando la secuencia de rocas volcánicas y sedimentarias del Valle Central y presenta una aureola de metamorfismo considerable.

Valverde (1989) reporta la presencia de tonalitas, monzodioritas, monzogabros, gabros, granodioritas con biotita y sienitas. Berrangé y Wittaker (1977) describen ampliamente las rocas afectadas por metamorfismo de contacto, determinando la presencia de cornubianitas y metamorfismo diferencial entre rocas sedimentarias, tanto en el cuadrante Tapantí como en el cuadrante Pejibaye. MacMillan, Gans y Alvarado (2004) reportan un gabro hornbléndico y una granodiorita con hornblenda y biotita.

Tanto los afloramientos visitados, como los bloques observados en los cauces de los ríos, muestran la presencia de autolitos y xenolitos con tamaños de hasta $50 \mathrm{~cm}$ y diques sin-magmáticos de espesores variables en el orden de $20 \mathrm{~cm}$. Se determinó que la unidad se divide en varios cuerpos intrusivos aislados, aflorando a lo largo del río Navarro, Sombrero y Grande de Orosi y al N de El Empalme y en el Alto Tres Picos. 
Normalmente, la aureola de metamorfismo se presenta asociada a los cuerpos intrusivos de mayor tamaño, presentes hacia la parte central y SE del cuadrante.

\section{Edad}

MacMillan, Gans y Alvarado (2004) realizan 3 dataciones Ar/Ar obteniendo edades entre 4,20 a 3,89 Ma.

\section{Correlación con otras unidades y áreas}

El intrusivo se encuentra cortando toda la secuencia de sedimentos del Valle Central y a la Formación La Cruz. Se estima que es un equivalente lateral del Intrusivo de Escazú, debido a las edades de ambos cuerpos, a su alineamiento y a sus similitudes litológicas.

\section{Génesis}

Alvarado y Gans (2012) sugieren que forman parte de uno de los últimos pulsos magmáticos generados en la cordillera de Talamanca.

\section{Aureola de Metamorfismo}

Debido a la interacción del basamento rocoso (sedimentos de la cuenca de Candelaria y arco volcánico del Mioceno) con las fases intrusivas desarrolladas en el área, se derivó una aureola de metamorfismo de contacto, presentando principalmente rocas conocidas como cornubianitas.

\section{Estratotipo}

Escalante (1969) fue el primero en describir este tipo de litología, la cual, según el autor, presenta buenos afloramientos en los caminos que conducen al P.H. Río Macho (561500-186800). En el presente trabajo, se corroboraron dichos afloramientos y, además, se determinó la presencia de esta litología en el sector SW del cuadrante.

\section{Descripción}

Dicha aureola presenta dos litologías principales, una generada a partir de rocas sedimentarias y otra a partir de rocas volcánicas. Las primeras son cornubianitas, que en general presentan tonalidades que van de verde a gris, muestran una profunda silicificación y mineralizaciones de pirita. Cuando la roca original era volcánica, las rocas muestran tonalidades grisáceas, mineralizaciones de pirita y generalmente produce suelos con tonalidades blancuzcas y moradas.

\section{Edad}

Según la interacción de las rocas preexistentes con las fases intrusivas se infieren dos edades; Mioceno Superior para las rocas aflorantes al SW del cuadrante, y Plioceno para las cornubianitas aflorantes en la parte central del cuadrante.

\section{Correlación con otras Unidades y áreas}

Se presenta como producto del metamorfismo de contacto, derivado de la interacción con las fases intrusivas, así que se infiere un contacto lateral entre cornubianitas e intrusivos.

\section{Formación Grifo Alto}

Posterior a la tectónica de final del Mioceno, ocurre un vulcanismo representado por esta unidad geológica, el cual se asocia con el arco volcánico del Plioceno. 


\section{Estratotipo}

Denyer y Arias (1991) describen por primera vez a esta formación, y asignan al poblado de Grifo Alto como localidad tipo. En el cuadrante Tapantí se le ha identificado hacia el sector W-SW, y los mejores afloramientos se observan en la localidad de La Lucha.

\section{Descripción}

Denyer y Arias (1991) la describen como una serie de rocas volcánicas andesíticas y piroclásticas. Barrantes (1991) detalla en aspectos petrográficos y determina que las rocas varían desde basaltos a andesitas, con predominancia de las últimas. En el área de estudio se observan coladas de lavas y brechas, que en general muestran tonos oscuros y un alto grado de meteorización. Se encuentran aflorando en un área de $15 \mathrm{~km}^{2}$. Macroscópicamente, las lavas se describen como andesitas con fenocristales de plagioclasa y una matriz oscura.

Presenta un espesor de al menos $300 \mathrm{~m}$ y normalmente está afectada por alteración hidrotermal en las cercanías de la carretera Interamericana.

\section{Edad}

Denyer y Arias (1991) le asignan un rango de edad Plioceno, basados en relaciones estratigráficas y dataciones radiométricas, posteriormente, Marshall et al. (2003) aportan edades de 5,5-5,0 Ma. MacMillan, Gans y Alvarado (2004) y Alvarado y Gans (2012) realizan varias dataciones por medio del método $\mathrm{Ar} / \mathrm{Ar}$ para varias muestras en las cercanías del área de estudio (cuadrantes Río Grande, Caraigres y Abra) y determinan que dicha formación se produjo desde hace 7,3 hasta los 3,3 Ma (Mioceno superior terminal-Plioceno).

\section{Correlación con otras Unidades y áreas}

Según Denyer y Arias (1991), la Formación Grifo Alto sobreyace por medio de una discordancia angular a toda la secuencia sedimentaria del Valle Central y a la Formación La Cruz, mientras que las rocas asociadas al arco volcánico actual sobreyacen discordantemente a la Formación Grifo Alto.

\section{Génesis}

Esta unidad geológica se depositó después del basculamiento de finales del Mioceno y antes de la instauración del arco magmático en la posición que ocupa actualmente (Denyer y Arias, 1991). Su génesis se asocia al vulcanismo generado a partir del arribo de la dorsal de Cocos a la fosa mesoamericana.

\section{Formación Doán}

Esta unidad corresponde con la destrucción de los aparatos volcánicos anteriores al arco magmático actual.

\section{Estratotipo}

Escalante (1966) define a la Formación Doán basado en el nombre del cerro Doán, situado en la esquina sureste del cuadrante Tapantí. Otros afloramientos importantes se pueden apreciar en el cauce del río Reventazón, en las cercanías del embalse Cachí (Fig. 6 A y B).

\section{Descripción}

Escalante (1966) define por primera vez a la Formación Doán, mientras que Umaña (1966) describe la misma litología con el nombre de 

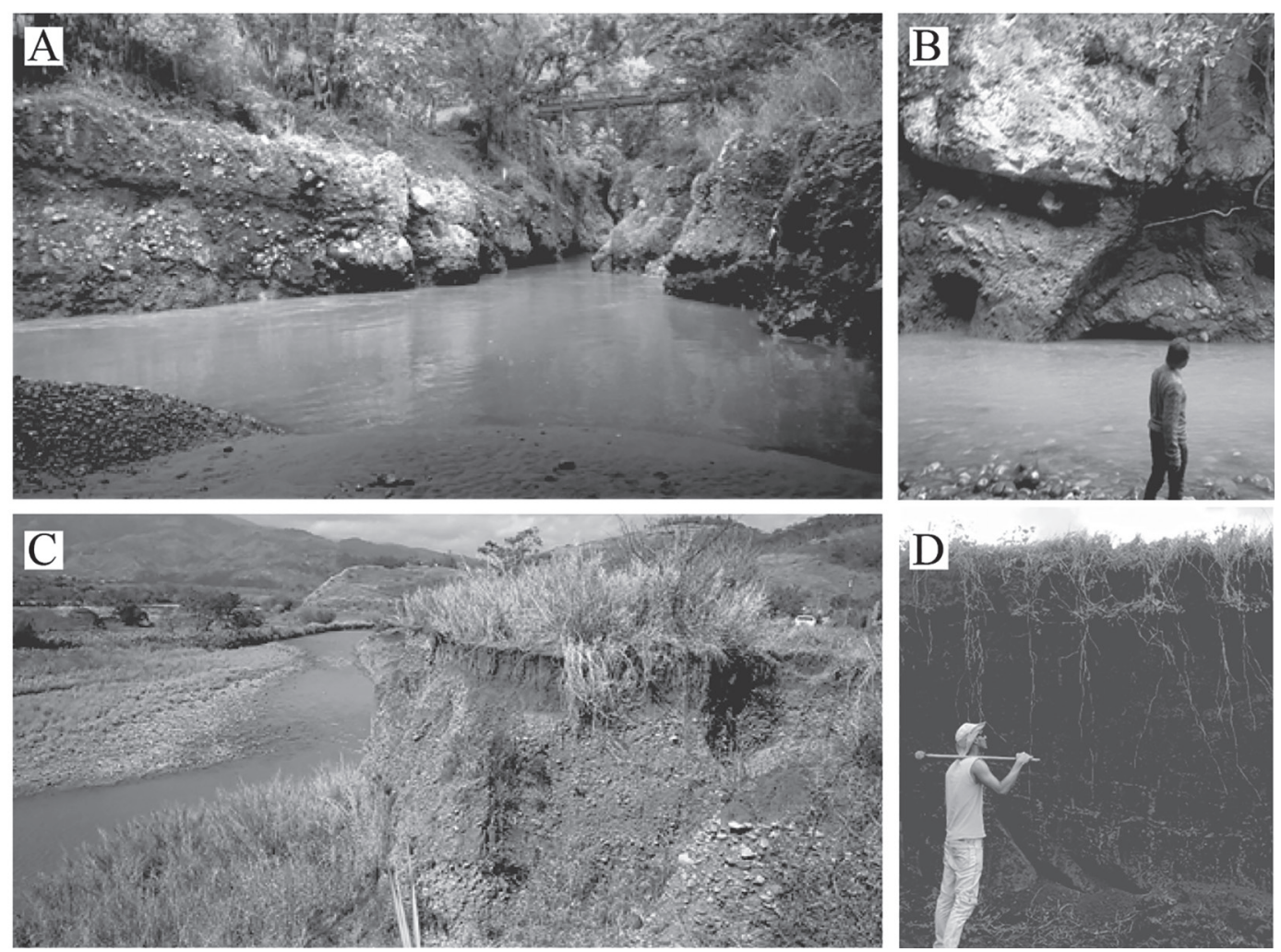

Fig. 6: A y B. Afloramientos de la Formación Doán, río Reventazón. C. Afloramientos de la Formación Ujarrás, poblado de Ujarrás. D. Afloramiento de la Formación Paraíso, poblado La Joya.

Formación Peñas Blancas. Por otra parte, Dóndoli y Torres (1954) reportan descripciones de litologías asociables a esta unidad.

Alvarado y Pérez (1998) describen a la Formación Doán como una masa de al menos $800 \mathrm{~m}$ de espesor, compuesta en un $80 \%$ de rocas clásticas y un $20 \%$ restante de lavas y diques subordinados. Los depósitos líticos corresponden con depósitos de flujos de bloques y cenizas, flujos ricos en cristales y líticos, posibles avalanchas volcánicas e intercalaciones de capas de cenizas. Además, contiene extensos depósitos epiclásticos, los cuales consisten en depósitos de flujos de escombros, tobitas, conglomerados y brechas tobáceas. Las coladas de lava consisten en basaltos hasta andesitas y traquiandesitas basálticas.

El presente trabajo agrega además datos cartográficos, petrográficos y geoquímicos de esta formación. Esta formación aflora en toda la esquina NE del cuadrante Tapantí, donde se encuentra afectada por las varias fallas y alteración sericítica. La unidad presenta varias capas con inclinaciones de hasta $30^{\circ}$, en diferentes direcciones, morfología pronunciada y presencia de fenocristales de augita en la mayoría de sus facies.

Sojo (2015) realizó el análisis petrográfico de 8 muestras, donde resalta la presencia de vidrio incoloro, cristales hipidiomórficos de plagioclasa y dos tipos de piroxeno con longitudes de hasta 2 $\mathrm{cm}$ y algunos cristales de olivino. La textura de la matriz varía desde hialopilítica a pilotaxítica, y en general las muestras se presentan relativamente sanas, con algunos feldespatos afectados a sericita.

La presencia de diques ha sido reportada en varios trabajos, y en el presente se logró ubicar un enjambre de diques cerca de las coordenadas 
558450-201900, en la localidad de La Laja. Se trata de un grupo de al menos 4 diques cortando las rocas de la Formación Doán, con espesores mínimos de $2 \mathrm{~m}$ y composición andesítica hasta basáltica. Por otra parte, en las cercanías del cerro Doán, se logró identificar un afloramiento de gabro. En general se interpreta que dichos intrusivos se asocian a la actividad volcánica de la formación.

\section{Edad}

Según Alvarado y Pérez (1998) su edad es del inicio del Plioceno, basados en la posible relación lateral con la Formación Suretka.

\section{Correlación con otras unidades y áreas}

No se ha encontrado su contacto inferior en afloramiento, por lo cual el mismo ha sido inferido como una discordancia con los sedimentos neógenos y con el vulcanismo del Mioceno.

Sus contactos superiores se dan con la Formación Ujarrás, Paraíso, y Cervantes, las cuales sobreyacen discordantemente a la Formación Doán.

\section{Génesis}

Alvarado y Pérez (1998) lo relacionan con una fase orogénica desarrollada en el neógeno y al rápido levantamiento y destrucción del arco magmático. Este evento es correlacionable con eventos de vulcanismo adakítico (Sojo, 2015) y alcalino, el cual está relacionado con la interacción del arco de islas preexistente y el punto caliente de las islas Galápagos.

\section{Formación Suretka}

Esta formación corresponde con la acumulación fluvial producto del levantamiento de la cordillera de Talamanca, cuyas mejores exposiciones se encuentran en la cuenca de Limón.

\section{Estratotipo}

Su localidad tipo se encuentra en el poblado de Suretka, en Baja Talamanca, en la provincia de Limón (Hoffstetter et al., 1960, Taylor, 1975). En el área de estudio aflora en las cercanías de las tomas del PH. Río Macho, sobre el túnel que conecta el río Pejibaye con el río Grande de Orosi. Valverde (1989) la describe por primera vez en el cuadrante Tapantí y tuvo acceso a afloramientos ahora cubiertos.

\section{Descripción}

Esta formación está constituida por conglomerados y brechas polimícticas, con clastos de hasta $2 \mathrm{~m}$ de diámetro con intercalaciones de areniscas (Bottazzi, 2016), Los clastos son redondeados a subredondeados, en su mayoría sedimentarios a metamórficos (cornubianita), y en menor proporción fragmentos ígneos. La matriz es areno-arcillosa, amarillenta con un grado de cementación silícea variable. Presenta una forma tabular, con un espesor de hasta $150 \mathrm{~m}$ según sondeos de refracción sísmica (Valverde, 1989).

\section{Edad}

Hoffsteter et al. (1960) consideran una variación de edad entre el Mioceno al Pleistoceno. Taylor (1975) indica una edad del Pleistoceno a Reciente. Para las rocas aflorantes en el área de estudio, Valverde (1989), asigna una edad de Plioceno, lo cual es consistente con los tipos de sedimentos que componen a esta formación, debido a que incluye rocas metamórficas formadas por la alteración producida por el Intrusivo de Tapantí (4,3 Ma). Bottazzi (2016) la considera Plio-Pleistoceno.

\section{Correlación con otras unidades y áreas}

Debido a la dificultad de acceso de afloramientos ha sido complicado identificar contactos 
de esta formación. Valverde (1989) la describe sobreyaciendo discordantemente a la secuencia sedimentaria y al Intrusivo de Tapantí.

\section{Génesis}

Taylor (1975) indica un ambiente de depositación fue continental (canales, imbricaciones, discordancias erosivas). Bottazzi (2016) indica que la Formación Suretka tiene una zonificación que va de abanicos de pie de monte, en los sectores más proximales a la cordillera de Talamanca, hasta llanuras aluviales en los sectores más distales. Dicha depositación se vio impulsada por el levantamiento de la cordillera de Talamanca y su rápida erosión.

\section{Formación Paraíso}

Con esta unidad geológica se inicia la influencia de la cordillera volcánica Central y, específicamente del volcán Irazú. Se encuentra asociada a lo que Alvarado y Gans (2012) reconocen como "Proto-Irazú".

\section{Estratotipo}

Dondoli y Torres (1954) describen por primera vez a esta formación, definiendo como estratotipo a el camino que comunica a Paraíso con Orosi (Fig. 6 D) y la catarata Los Novios, por el antiguo camino que comunicó a Paraíso con Cachí (cuadrante Tapantí e Istarú respectivamente). Berrangé y Whittaker (1977) utilizan esta misma localidad para su trabajo en el cuadrante Tapantí.

\section{Descripción}

Dondoli y Torres (1954) la describen como una colada de lava andesítica cubierta por tobas y depósitos lacustres. Umaña (1966) y Escalante (1966) la definen como una colada de lava andesítica hasta basáltica con estructuras columnares.
Krushensky (1972) divide a este grupo de rocas como el Miembro Paraíso y el Miembro Capa de Ceniza, pertenecientes a la Formación Reventado, del Grupo Irazú. Berrangé y Wittaker (1977) y Sojo (2015) consideran que los materiales del Miembro Capa de Ceniza en realidad corresponden con laterita producto de la meteorización de las lavas y brechas subyacentes, por lo que debe abandonarse el uso de esta unidad.

En el cuadrante Tapantí, la Formación Paraíso está representada por una serie de coladas de lava y brechas andesíticas y un fuerte espesor de laterita (hasta $10 \mathrm{~m}$ ). Los afloramientos muestran una serie de rocas con fenocristales de plagioclasas y piroxenos, matriz color gris oscuro y presencia de disyunción laminar en la localidad tipo y disyunción columnar en el afloramiento de la catarata los Novios. Petrográficamente, las rocas se clasifican como andesitas basálticas y andesitas. Es común la presencia de fenocristales de plagioclasa, augita y olivinos, mientras que la textura de la matriz es andesítica en la mayoría de muestras analizadas, las cuales además no presentan minerales de alteración.

Se determinó que esta formación se encuentra basculada como mínimo unos $2^{\circ}-3^{\circ}$ (en el sector de Paraíso, mientras que en las cercanías del poblado de Ujarrás fue posible observar una grado mayor de deformación) con dirección N-NE, es de forma tabular y presenta un espesor variable que alcanza un máximo de unos $200 \mathrm{~m}$.

\section{Edad}

Escalante (1966) deduce, con base en las relaciones estratigráficas con la Formación Ujarrás, que su edad es más bien de Pleistoceno. Alvarado et al. (2006) realizan una datación radiométrica $\mathrm{Ar} / \mathrm{Ar}$, que revela una edad de 0,59-0,54 Ma.

\section{Correlación con otras Unidades y áreas}

En el cuadrante Tapantí, la Formación Paraíso sobreyace por medio de una discordancia angular a las formaciones Pacacua (Berrangé y Wittaker, 1977) y La Cruz. 
Génesis

Alvarado y Gans (2012) consideran que estas rocas se encuentran asociadas a las primeras efusiones del volcán Irazú, y corresponde con lo que denominan el Paleovolcán Irazú.

\section{Formación Ujarrás}

Como una consecuencia de la actividad volcánica, principalmente del volcán Irazú, se produjeron una serie de afectaciones del sistema de drenaje, lo que se traduce en depósitos lacustres en el registro geológico.

\section{Estratotipo}

Estas rocas son inicialmente descritas por Dóndoli y Torres (1954); posteriormente, Escalante (1966) define a la Formación Ujarrás y determina que sus mejores afloramientos se encuentran en las orillas de ríos y quebradas que drenan al valle de Ujarrás (Fig. 6 C).

\section{Descripción}

Dóndoli y Torres (1954) la describen como una serie de depósitos paleolacustres. Umaña (1966) coincide con tal descripción, mientras que Escalante (1966) considera que también se intercalan depósitos aluviales con presencia de capas de arcilla, arenas, limos y conglomerados con clastos de hasta $1 \mathrm{~m}$ de diámetro. Krushensky (1972) se basa en las descripciones anteriores para caracterizar los afloramientos de esta unidad al SE del cuadrante Istarú. Berrangé y Wittaker (1977) profundizan en la descripción de estos sedimentos y señalan que los clastos normalmente están compuestos por granodioritas, andesitas, areniscas y brechas. Determinan que dichos presentan tamaños de hasta $2 \mathrm{~m}$, y que algunas capas poseen imbricación y paleocanales.

En el presente trabajo estima que se trata de una formación acuñada hacia el $\mathrm{N}$, con un espesor que puede alcanzar hasta los $80 \mathrm{~m}$ según la interpretación estratigráfica y se logró determinar la existencia de al menos dos niveles de terrazas, con una diferencia de altura promedio de $25 \mathrm{~m}$. En general los depósitos presentan tonalidades amarillas, granulometría variable desde arenas hasta conglomerados con bloques de hasta $1 \mathrm{~m}$ de diámetro, dichos componentes se presentan subredondeados y están compuestos por materiales ígneos, metamórficos y sedimentarios.

\section{Edad}

Escalante (1966) le asigna una edad de Pleistoceno.

\section{Estructuras sedimentarias}

Paleocanales, clastos imbricados.

\section{Correlación con otras unidades y áreas}

Según las descripciones realizadas por Umaña (1966), para las perforaciones de investigación en el sitio de presa de Cachí, esta unidad se encuentra subyaciendo a la Formación Cervantes, lo cual puede ser observado cuando el nivel de la presa baja durante el verano.

\section{Génesis}

Dóndoli y Torres (1954) sugieren que su origen está relacionado a las coladas de lavas de la Formación Paraíso lo cual pudo haber colapsado el sistema de drenaje de los ríos preexistentes y provocado que se depositaran sedimentos fluvio lacustres. Escalante (1966) relaciona su origen con el relleno de una depresión "Volcano-tectónica", la cual se colmató durante el Pleistoceno.

\section{Formación Cervantes}

Representa coladas de lavas salidas de una serie de conos adventicios en el flanco sur del 
volcán Irazú, muy fácilmente distinguible, sea en el campo o en fotos aéreas.

\section{Estratotipo}

Dóndoli y Torres (1954) describen las rocas de esta formación proponiendo como localidad tipo a una serie de afloramientos expuestas en el poblado de Cervantes, mientras que Escalante (1966) describe afloramientos en las cercanías de los poblados del Yas, Piedra Azul, Santiago y el sitio de presa de Cachí. Krushensky (1972) define formalmente a estas rocas como Formación Cervantes.

Berrangé y Wittaker (1977) y Sojo (2015) señalan que esta litología se presenta en una pequeña porción en el cuadrante Tapantí, en las cercanías del sitio de presa de Cachí.

\section{Descripción}

Dóndoli y Torres (1954) la describen como una serie de coladas de andesitas color gris, con textura vesicular. Umaña (1966) y Escalante (1966) señalan además la presencia de disyunción columnar, textura escoriácea y relieve irregular. Alvarado et al. (2006) afirman que se trata de andesitas basálticas con fenocristales de plagioclasa, clinopiroxenos y algunos olivinos y titanomagnetita en una matriz compuesta principalmente por microlítos de plagioclasa, ilmenita y vidrio riolitico. Alvarado y Vega (2013) describen las morfologías presentadas por esta formación, definiendo la existencia de un túnel de lava, kippukas, depresiones y centros de emisión. Por otra parte, determinan que el espesor de esta unidad es irregular y alcanza un máximo de unos $80 \mathrm{~m}$.

\section{Edad}

Según una datación radiométrica $\mathrm{Ar} / \mathrm{Ar}$ esta formación presenta una edad de 0,02 a 0,017 Ma (Alvarado et al., 2006).

\section{Paleontología}

Alvarado et al. (2006) reportan la presencia de materia orgánica calcinada hacia la base de esta unidad.

\section{Correlación con otras unidades y áreas}

En el área de estudio se le observa sobreyaciendo discordantemente a la Formación Ujarrás (Sojo, 2015).

\section{Génesis}

$\mathrm{Su}$ génesis se encuentra relacionada con los últimos eventos del volcán Irazú y ha sido emanada desde un cono parásito de dicho volcán, el cual se asocia con un alineamiento N-S (Alvarado et al. 2006) de varios conos parásitos.

\section{Depósitos de coluvios}

Los depósitos que presentan un tamaño visible para la escala de trabajo afloran principalmente en las cercanías de las trazas de las fallas Agua Caliente, Navarro y Orosi. Son depósitos de caída por gravedad, presentan tamaños variados con clastos de hasta $8 \mathrm{~m}$ de diámetro, en general angulosos y con una matriz areno-arcillosa.

\footnotetext{
Abanicos aluviales

Se presentan en asocio a los depósitos de coluvios y a los aluviones y están asociados a los mayores escarpes alineados, principalmente con la traza de falla Orosi en la localidad de Orosi y Navarro y en la localidad de Cachí. El valle de Ujarrás ha estado expuestos a flujos de lodo con escombros, asociados a deslizamientos, que se evidencian en 8 abanicos (Salazar et al., 1992), dentro de ellos destacan la quebrada Tanque y los ríos Macho y Jucó. Valga citar ejemplos recientes en Alto Loaiza en el 2002 y en la quebrada Granados desde el 2004 (Mora, 2010).
} 


\begin{abstract}
Aluvión
Corresponden con los sedimentos transportados y depositados en los cauces estrechos de los ríos Reventazón, Grande de Orosi y Navarro. La depositación mayor se ha dado en el colector principal, que es el río Reventazón, que tiene una afectación antropogénica porque parte del cauce está cubierto por el embalse de la represa Cachí (ver mapa Geológico). En general los clastos presentan tamaños de hasta $5 \mathrm{~m}$ de diámetro, composición variable y bajo grado de redondez, con una matriz arenosa.
\end{abstract}

\section{GEOQUÍMICA}

Gazel et al. (2009) indican como el arribo de la cordillera de Coco a la fosa mesoamericana genera un cambio en las características de la composición del magma, notable a partir de los 10 - $6 \mathrm{Ma}$, donde las rocas analizadas presentan un enriquecimiento en $\mathrm{Si}$ y K, lo que finalmente es relacionado con el proceso de evolución de la corteza oceánica a corteza continental o "continentalización" (Gazel et al., 2015). El presente trabajo busca delimitar tal proceso evolutivo para las rocas aflorantes en el cuadrante Tapantí, por lo cual se trabajó con muestras correspondientes a las unidades ígneas del área (17 en total). Los datos presentados (1) muestran la abundancia de elementos mayores y traza, los cuales fueron obtenidos a partir de XRF y espectrometría de masas (Cuadro 1).

De acuerdo con el diagrama Irvine y Baragar (1971), las rocas volcánicas de las formaciones Grifo Alto, Doán, Paraíso y el Intrusivo de Tapantí se concentran predominantemente en la serie calco-alcalina, mientras que las muestras asociadas a la Formación La Cruz y el Intrusivo de Dota presentan un carácter toleítico (Fig. 7 A). El vulcanismo del área de estudio presenta un espectro geoquímico relativamente restringido, entre una naturaleza básica hasta intermedia y está representado por basaltos, andesitas basálticas, andesitas y traquiandesitas basálticas (Fig. 7 B).
Los basaltos están representados principalmente por rocas de las formaciones Doán y La Cruz, mientras que las rocas con mayores concentraciones de $\mathrm{K}$ presentan características intermedias.

La figura $5 \mathrm{C}$ muestra la relación $\mathrm{Zr} / \mathrm{Nb}$ y Ba/ La para las fuentes mantélicas de las muestras de las rocas volcánicas, donde $\mathrm{Zr} / \mathrm{Nb}$ aumenta conforme aumenta el Ba/La. Gazel et al. (2009) utilizan esta relación para trabajar con rocas similares a las del presente trabajo y afirman que la tendencia, hacia la fuente mantélica OIB, corresponde a la contaminación con la firma geoquímica de las islas Galápagos, por medio de la cordillera de Coco, lo cual es notable en rocas con edades menores de 8 Ma.

El diagrama de $\mathrm{Ba} / \mathrm{La}$ vs $\mathrm{La} / \mathrm{Yb}$ (Fig. 7 E) (Cameron et al., 2003) utilizado para mostrar las diferencias que ocurren como resultado del aporte de fluidos de la placa (que se subduce) versus los procesos de fusión, donde, $\mathrm{La} / \mathrm{Yb}$ incrementa con la adición de material cortical a los fundidos del manto, y a su vez aumenta con el descenso del porcentaje de fusión de la roca fuente, que puede ser material de la corteza o manto. Las muestras con $\mathrm{La} / \mathrm{Yb}>10$ se originaron a partir de bajos grados de fusión parcial del manto (o una derivación de una fuente enriquecida (Gazel et al., 2009)) y poseen una afinidad OIB concordante con los patrones altos de REE de las lavas eruptadas de la parte central de Costa Rica (Carr et al., 1990).

Según los valores de la Figura 7 D, la razón U/Th tiende a ser inferior a 0,5 para rocas con edades menores a 8 Ma (Paraíso, Doán y Grifo Alto), lo cual coincide con lo expuesto por Saginor et al. (2013), quien indica que la razón U/Th decae alrededor de los 12 - $9 \mathrm{Ma}$, lo cual se relaciona con un menor aporte del componente hemipelágico en el magmatismo de arco, y a un cambio en las condiciones de la subducción, o bien el arribo de la cordillera de Coco.

Un enriquecimiento en LILE se da en la normalización a condrito según Sun et al. (1980) (Fig. 7 F), donde predominan los elementos que se concentran en la fase líquida del manto (incompatibles), con lo que se evidencia 
Cuadro 1

Resumen de los análisis geoquímicos de elementos traza (ppm) y mayores (\%).

\begin{tabular}{|c|c|c|c|c|c|c|c|c|c|c|c|c|c|}
\hline Muestra & Unid. & $\mathrm{SiO}_{2}$ & $\mathrm{P}_{2} \mathrm{O}_{5}$ & $\mathrm{Al}_{2} \mathrm{O}_{3}$ & $\mathrm{Fe}_{2} \mathrm{O}_{3}$ & $\mathrm{MnO}$ & $\mathrm{MgO}$ & $\mathrm{CaO}$ & $\mathrm{Na}_{2} \mathrm{O}$ & $\mathrm{K}_{2} \mathrm{O}$ & $\%$ tot. & $\mathrm{Yb}$ & $\mathrm{Pb}$ \\
\hline $1-151014$ & Paraíso & 58,0 & 0,3 & 17,46 & 6,99 & 0,1 & 3,46 & 5,92 & 3,41 & 2,53 & 99,2 & 1,82 & 8,43 \\
\hline $2-151014$ & Paraíso & 56,2 & 0,35 & 17,6 & 8,37 & 0,13 & 3,72 & 6,32 & 3,53 & 2,4 & 99,9 & 2,44 & 7,4 \\
\hline DK2 & La Cruz & 51,6 & 0,17 & 19,35 & 10,36 & 0,18 & 3,77 & 10,31 & 2,75 & 0,81 & 100 & 2,43 & 3,12 \\
\hline D-1 & Doán & 52,0 & 0,29 & 17,35 & 8,01 & 0,14 & 6,84 & 9,31 & 3,44 & 1,15 & 99,41 & 1,16 & 4,36 \\
\hline D-2 & Doán & 54,9 & 0,27 & 17,97 & 7,23 & 0,1 & 4,4 & 7,33 & 3,79 & 1,23 & 98,1 & 0,84 & 4,75 \\
\hline D-3 & Doán & 50,0 & 0,18 & 17,51 & 8,49 & 0,13 & 6,55 & 10,71 & 3,09 & 0,95 & 98,55 & 1,23 & 4,74 \\
\hline D-4 & Doán & 49,5 & 0,17 & 17,11 & 8,87 & 0,14 & 7,08 & 10,84 & 2,9 & 0,92 & 98,49 & 1,19 & 4,11 \\
\hline D-7 & Doán & 52,6 & 0,28 & 18,34 & 8,25 & 0,17 & 4,32 & 9,23 & 3,6 & 1,1 & 98,87 & 1,2 & 4,73 \\
\hline D-10 & Doán & 50,8 & 0,36 & 17,12 & 8,76 & 0,15 & 6,6 & 9,38 & 3,3 & 1,19 & 98,66 & 1,26 & 3,94 \\
\hline Dike-1 & Doán & 61,0 & 0,37 & 18,44 & 5,45 & 0,06 & 2,26 & 5,78 & 4,4 & 1,72 & 100 & 1,02 & 8,66 \\
\hline DT-IN & Dota & 61,3 & 0,2 & 16,6 & 7,09 & 0,15 & 2,26 & 4,89 & 3,87 & 3,47 & 100 & 3,53 & 9,53 \\
\hline Gb-dot & Dota & 49,5 & $-0,19$ & 20,45 & 10,79 & 0,19 & 4,1 & 11,11 & 2,09 & 0,21 & 98,95 & 1,57 & 0,86 \\
\hline TP-1-2 & La Cruz & 48,9 & 0,16 & 18,62 & 11,65 & 0,21 & 4,76 & 9,96 & 2,92 & 0,66 & 98,93 & 2,42 & 1,94 \\
\hline TP-IN & Tapantí & 61,8 & 0,23 & 16,66 & 5,81 & 0,12 & 2,44 & 4,89 & 3,19 & 4,55 & 100 & 2,98 & 16,4 \\
\hline GB-Pur & Tapantí & 53,8 & 0,24 & 19,61 & 8,82 & 0,18 & 3,78 & 8,91 & 2,86 & 0,74 & 99,55 & 1,81 & 3,34 \\
\hline DKA & La Cruz & 51,3 & 0,25 & 19,45 & 10,2 & 0,2 & 3,74 & 9,91 & 2,94 & 0,9 & 99,89 & 2,52 & 2,55 \\
\hline $2-141014$ & Grifo Alto & 53,4 & 0,3 & 17,86 & 8,83 & 0,23 & 3,69 & 7,62 & 2,74 & 2,69 & 98,27 & 2,44 & 7,63 \\
\hline Muestra & Unidad & $\mathrm{Sc}$ & V & $\mathrm{Cr}$ & $\mathrm{Co}$ & $\mathrm{Ni}$ & $\mathrm{Cu}$ & $7 \mathrm{n}$ & $\mathrm{Gl}_{2}$ & $\mathrm{Ge}$ & $\mathrm{Rb}$ & $\mathrm{I}_{1}$ & $\mathrm{Ta}$ \\
\hline $1-151014$ & Paraíso & 31,68 & 175,5 & 57,03 & 21,65 & 38,44 & 120,3 & 88,6 & 29,29 & 1,26 & 71,57 & 0,24 & 1,09 \\
\hline $2-151014$ & Paraíso & 30,1 & 207 & 82,4 & 25,1 & 38,9 & 247 & 108 & 40,5 & 1,6 & 65,5 & 0,36 & 1,33 \\
\hline DK2 & La Cruz & 32,83 & 268,7 & 15,88 & 26,01 & 11,77 & 44,9 & 96,07 & 18,49 & 1,63 & 11,16 & 0,37 & 0,08 \\
\hline D-1 & Doán & 29,5 & 229,8 & 262,4 & 32,48 & 126,3 & 155,5 & 92,58 & 26,68 & 1,19 & 17,73 & 0,17 & 0,39 \\
\hline D-2 & Doán & 28,06 & 213,3 & 115,3 & 25,74 & 60,03 & 94,4 & 89,38 & 26,67 & 1,06 & 18,92 & 0,12 & 0,24 \\
\hline D-3 & Doán & 32,18 & 274,5 & 169,8 & 33,11 & 60,18 & 241,9 & 89,22 & 22,37 & 1,24 & 14,76 & 0,17 & 0,28 \\
\hline D-4 & Doán & 33,03 & 288,8 & 175,7 & 33,98 & 58,01 & 111,4 & 96,11 & 22,07 & 1,28 & 13,49 & 0,2 & 0,31 \\
\hline D-7 & Doán & 29,88 & 244,4 & 47,26 & 27,92 & 31,74 & 77,7 & 96,72 & 26,78 & 1,13 & 16,48 & 0,17 & 0,39 \\
\hline D-10 & Doán & 30,52 & 237,0 & 246,8 & 34,31 & 126,4 & 74,9 & 91,67 & 26,11 & 1,24 & 18,91 & 0,17 & 0,65 \\
\hline Dike-1 & Doán & 28,97 & 120,8 & 15,71 & 14,21 & 17,44 & 147,7 & 96,3 & 36,55 & 1,15 & 34,36 & 0,18 & 0,64 \\
\hline DT-IN & Dota & 32,82 & 137,0 & 6,42 & 11,95 & 4,38 & 87,1 & 98,86 & 37,43 & 1,52 & 95,5 & 0,56 & 0,68 \\
\hline Gb-dot & ota & 34,76 & 310,2 & 4,52 & 27,73 & 6,74 & 77 & 81,06 & 12,81 & 1,31 & 1,92 & 0,27 & 0,02 \\
\hline TP-1-2 & La Cruz & 32,11 & 347,0 & 6,41 & 31,44 & 14,51 & 120,4 & 105,3 & 21,7 & 1,55 & 7,47 & 0,4 & 0,17 \\
\hline TP-IN & Tapantí & 29,76 & 123,6 & 23,7 & 15,08 & 12,54 & 105,7 & 89,7 & 31,12 & 1,36 & 161,3 & 0,52 & 1,31 \\
\hline GB-Pur & Tapantí & 29,52 & 182,1 & 10,3 & 24,01 & 1,2 & 118,6 & 110,5 & 32,04 & 1,47 & 12,75 & 0,28 & 0,09 \\
\hline DK A & La Cruz & 33,64 & 259,9 & 13,89 & 25,35 & 7,53 & 292,7 & 106,9 & 29,64 & 1,73 & 12,92 & 0,37 & 0,11 \\
\hline $2-141014$ & Grifo Alto & 32,05 & 230,8 & 5,83 & 26,54 & 0,91 & 178,1 & 109,3 & 42,6 & 1,7 & 73,6 & 0,42 & 0,57 \\
\hline
\end{tabular}


Cuadro 1 (continuación)

Resumen de los análisis geoquímicos de elementos traza (ppm) y mayores (\%).

\begin{tabular}{|c|c|c|c|c|c|c|c|c|c|c|c|c|c|}
\hline Muestra & Unidad & $\mathrm{Sr}$ & $\mathrm{Y}$ & $\mathrm{Zr}$ & $\mathrm{Nb}$ & $M o(R u)$ & W & $\mathrm{Cd}(\mathrm{Sn})$ & $\mathrm{Sn}(\mathrm{Te})$ & Cs & $\mathrm{Ba}$ & $\mathrm{La}$ & $\mathrm{U}$ \\
\hline $1-151014$ & Paraíso & 775,02 & 20,26 & 195,18 & 20,31 & 0,04 & 0,78 & 0,05 & 1,28 & 1,26 & 1015,09 & 45,43 & 4,06 \\
\hline $2-151014$ & Paraíso & 856,8 & 28,56 & 234,63 & 25,48 & 0,02 & & 0,08 & 1,74 & 0,79 & 1137,4 & 67,41 & 3,82 \\
\hline DK2 & La Cruz & 536,51 & 24,19 & 50,53 & 1,75 & 0,01 & 0,11 & 0,02 & 0,75 & 0,13 & 479,19 & 6,98 & 0,32 \\
\hline D-1 & Doán & 1273,55 & 12,58 & 75,63 & 6,98 & 0,01 & 0,26 & 0,06 & 0,92 & 0,23 & 868,24 & 24,78 & 1,04 \\
\hline D-2 & Doán & 1217,69 & 9,49 & 63,71 & 4,66 & 0,01 & 0,18 & 0,07 & 0,77 & 0,26 & 869,23 & 16,55 & 0,65 \\
\hline D-3 & Doán & 1116,54 & 13,45 & 53,25 & 5,51 & 0,01 & 0,19 & 0,07 & 0,82 & 0,15 & 638,98 & 15,69 & 0,65 \\
\hline D-4 & Doán & 1054,66 & 13,89 & 51,95 & 5,41 & 0,01 & 0,13 & 0,06 & 0,86 & 0,16 & 624,85 & 15,13 & 0,58 \\
\hline D-7 & Doán & 1290,01 & 17,25 & 67 & 7 & 0,01 & 0,18 & 0,06 & 0,91 & 0,16 & 828,69 & 22,26 & 0,85 \\
\hline D-10 & Doán & 1252,07 & 14,34 & 89,97 & 12,26 & 0,01 & 0,26 & 0,04 & 0,87 & 0,17 & 842,26 & 31,82 & 1,17 \\
\hline Dike-1 & Doán & 1372,61 & 11,77 & 116,51 & 10,86 & 0,02 & 0,39 & 0,04 & 0,68 & 0,36 & 1345,92 & 34,19 & 2,19 \\
\hline DT-IN & Dota & 446,54 & 31,82 & 251,57 & 12,8 & 0,01 & 1,21 & 0,03 & 1,39 & 1,71 & 1474,22 & 20,97 & 2,66 \\
\hline Gb-dot & Dota & 382,16 & 14,6 & 20,73 & 0,39 & 0,01 & 0,06 & 0,04 & 0,45 & 0,17 & 209,18 & 1,75 & 0,09 \\
\hline TP-1-2 & La Cruz & 750,37 & 24,74 & 48,99 & 2,09 & 0,01 & 0,11 & 0,02 & 0,79 & 0,06 & 630,52 & 8,64 & 0,27 \\
\hline TP-IN & Tapantí & 728,27 & 39,22 & 343,57 & 22,57 & 0,03 & 1,11 & 0,03 & 1,45 & 2,57 & 1201,17 & 55,75 & 6,32 \\
\hline GB-Pur & Tapantí & 910,08 & 17,27 & 45,23 & 1,94 & 0,01 & & 0,16 & 0,73 & 0,24 & 757,45 & 10,42 & 0,3 \\
\hline DKA & La Cruz & 547,44 & 23,73 & 51,9 & 1,8 & 0 & & 0,14 & 0,93 & 0,16 & 609,3 & 7,22 & 0,32 \\
\hline $2-141014$ & Grifo Alto & 1049,48 & 28,51 & 172,22 & 12,56 & 0,02 & & 0,09 & 1,46 & 0,64 & 1268,72 & 46,39 & 3,2 \\
\hline Muestra & Unidad & $\mathrm{Ce}$ & $\operatorname{Pr}$ & $\mathrm{Nd}$ & $\mathrm{Sm}$ & $\mathrm{Eu}$ & Hf & $\mathrm{Gd}$ & $\mathrm{Tb}$ & Dy & Ho & $\mathrm{Er}$ & Th \\
\hline $1-151014$ & Paraíso & 81,34 & 10,26 & 36,55 & 6,08 & 1,6 & 4,72 & 5,02 & 0,67 & 3,61 & 0,67 & 1,81 & 11,13 \\
\hline $2-151014$ & Paraíso & 100,72 & 15,4 & 56,3 & 9,47 & 2,33 & 5,71 & 7,55 & 1 & 5,34 & 0,99 & 2,73 & 12,44 \\
\hline DK2 & La Cruz & 14,05 & 2,51 & 12,23 & 3,46 & 1,22 & 1,56 & 4,2 & 0,65 & 4,3 & 0,85 & 2,53 & 0,62 \\
\hline D-1 & Doán & 45,57 & 6,17 & 24,41 & 4,57 & 1,33 & 2,03 & 3,75 & 0,47 & 2,6 & 0,45 & 1,14 & 3,24 \\
\hline D-2 & Doán & 30,01 & 4,36 & 18,06 & 3,29 & 1,04 & 1,78 & 2,61 & 0,34 & 1,87 & 0,35 & 0,85 & 1,46 \\
\hline D-3 & Doán & 31,54 & 4,55 & 19,46 & 3,94 & 1,16 & 1,49 & 3,37 & 0,43 & 2,61 & 0,49 & 1,32 & 1,64 \\
\hline D-4 & Doán & 31,65 & 4,55 & 19,55 & 3,91 & 1,19 & 1,55 & 3,22 & 0,44 & 2,75 & 0,49 & 1,35 & 1,66 \\
\hline D-7 & Doán & 40,41 & 5,55 & 22,57 & 4,36 & 1,28 & 1,84 & 3,66 & 0,48 & 2,62 & 0,51 & 1,37 & 2,34 \\
\hline D-10 & Doán & 57,55 & 7,34 & 29,64 & 5,06 & 1,5 & 2,26 & 4,52 & 0,55 & 2,74 & 0,49 & 1,28 & 3,88 \\
\hline Dike-1 & Doán & 59,69 & 7,2 & 25,98 & 3,98 & 1,22 & 2,72 & 3,15 & 0,4 & 1,96 & 0,36 & 1,05 & 4,64 \\
\hline DT-IN & Dota & 39,61 & 5,67 & 22,34 & 5,06 & 1,21 & 6,42 & 5,19 & 0,82 & 5,25 & 1,1 & 3,07 & 5,86 \\
\hline Gb-dot & Dota & 3,79 & 0,75 & 4,56 & 1,39 & 0,58 & 0,65 & 2,07 & 0,38 & 2,49 & 0,54 & 1,51 & 0,14 \\
\hline TP-1-2 & La Cruz & 17,89 & 2,94 & 13,92 & 3,94 & 1,34 & 1,51 & 4,33 & 0,71 & 4,31 & 0,88 & 2,45 & 0,5 \\
\hline TP-IN & Tapantí & 96,61 & 12,18 & 47,01 & 8,8 & 2,00 & 8,16 & 8,45 & 1,17 & 6,35 & 1,25 & 3,25 & 24,37 \\
\hline GB-Pur & Tapantí & 18,39 & 2,84 & 12,33 & 3,02 & 1,05 & 1,34 & 3,1 & 0,46 & 2,78 & 0,6 & 1,67 & 0,73 \\
\hline DKAl & La Cruz & 14,4 & 2,64 & 12,87 & 3,36 & 1,22 & 1,52 & 3,95 & 0,65 & 4,12 & 0,86 & 2,48 & 0,61 \\
\hline $2-141014$ & Grifo Alto & 81,32 & 10,54 & 40,81 & 7,33 & 1,82 & 4,02 & 6,29 & 0,88 & 4,55 & 0,91 & 2,45 & 10,06 \\
\hline
\end{tabular}



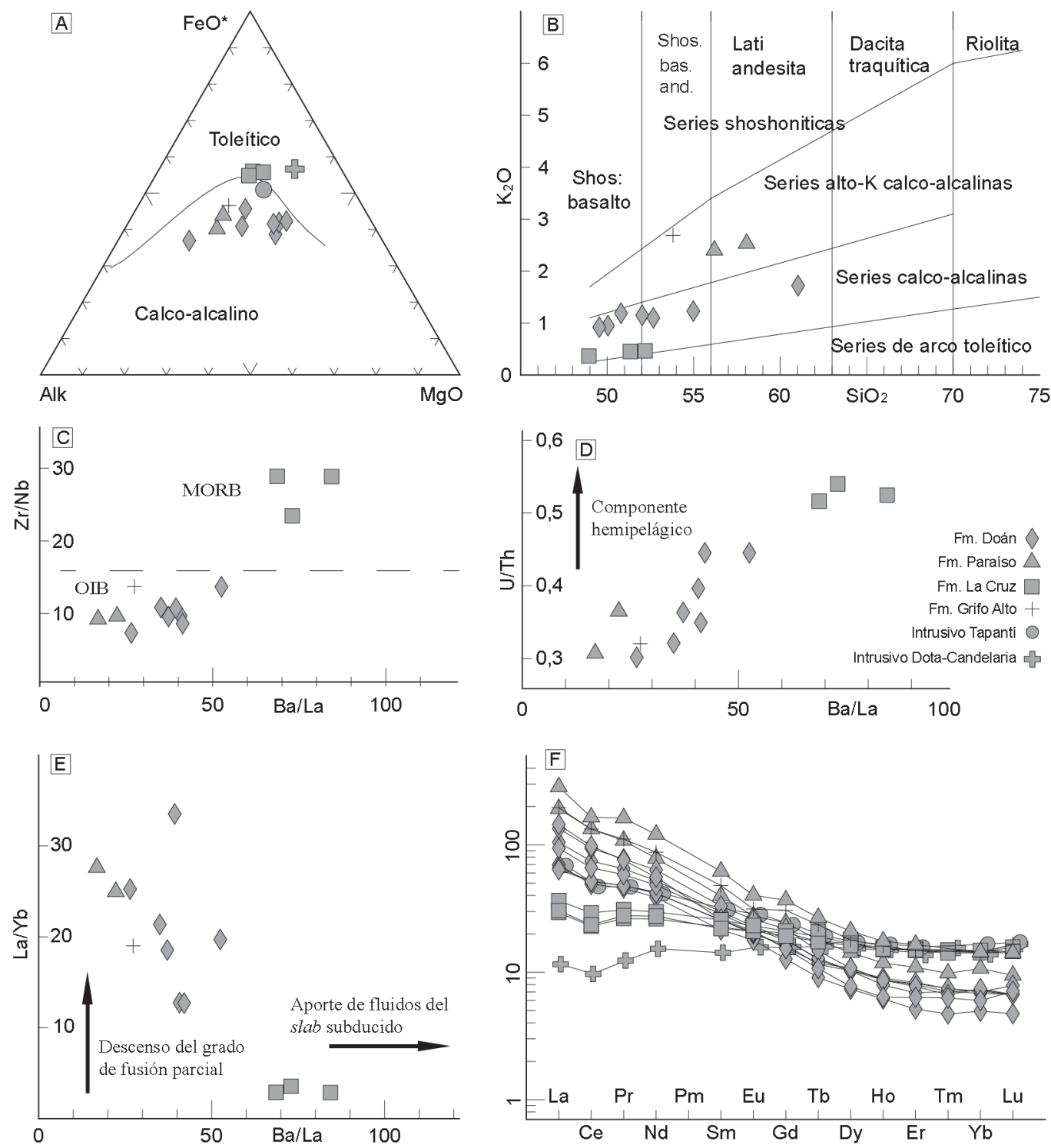

Fig. 7:. A: Diagrama Irvine y Baragar $(1971)\left({ }^{*} \mathrm{Fe}^{+3}\right)$. B: Diagrama Álcalis Totales/Sílice (TAS) para la clasificación geoquímica. C: Razones promedio Zr/Nb vs. Ba/La. D: Razones promedio U/Th vs. Ba/La. E: Razones promedio La/Yb vs. Ba/La. F: Diagramas Araña normalizados a condrito (Sun y McDonough, 1989).

la diferencia de patrones de REE entre las rocas estudiadas. Las rocas asociadas a la Formación La Cruz e Intrusivo de Dota (edades superiores a los $8 \mathrm{Ma})$ muestran un patrón semiplano con un leve enriquecimiento en LILE, mientras que el resto de rocas presenta un patrón de pendiente fuerte, mostrando un mayor enriquecimiento en las rocas de las formaciones Grifo Alto y Paraíso (0 - $6 \mathrm{Ma})$. 


\section{GEOLOGÍA ESTRUCTURAL}

El cuadrante Tapantí se encuentra ubicado dentro de la región tectónica conocida como el CDCCR (Fig. 1), descrito por Marshall et al. (2000) y Montero (2001), en el cual hay una predominancia de fallas sinestrales con orientación ENE y fallas dextrales con orientación NW. Arias y Denyer (1991) detallan que la región ha experimentado deformación con esfuerzos compresivos NS desde finales del Mioceno Superior, sobresaliendo un periodo de deformación durante el Mioceno Superior-Plioceno, el cual se ve reflejado por medio de una serie de pliegues presentes en los cuadrantes Abra, Istarú y Tapantí y por un basculamiento en la cuenca del río Candelaria. El presente trabajo muestra y describe dichos procesos que afectan al cuadrante (Fig. 8 y Mapa Geológico).

\section{Fallas}

Según los resultados obtenidos en el presente trabajo y la incorporación de los aspectos mostrados en trabajos anteriores, se tiene que las estructuras se presentan por medio de tres dominios estructurales; a) estructuras con orientación ENE, b) orientación NW y c) orientación NS. Las fallas ENE aparentan ser dominantes sobre las demás y su interacción ha propiciado las condiciones para un fuerte levantamiento y erosión, lo cual ha hecho que hacia la parte central del cuadrante afloren las unidades geológicas de mayor edad, a modo de "ventana".

\section{Fallas con orientación ENE}

Se presentan como las estructuras de mayor importancia en el área de estudio. Se consideran como las estructuras principales del cuadrante Tapantí. El grupo de fallas está compuesto por el Sistema de falla Navarro (determinado por
Montero, 1998), la falla Purisil y las fallas $\alpha$. Al menos dos de las estructuras (Navarro y Purisil) muestran un patrón en échelon, por medio de saltos derechos e izquierdos, generando morfologías importantes como lo es el área ocupada por Cachí y Ujarrás o Purisil, lo cual podría coincidir con cuencas de tipo tracción (Fig. 8).

\section{Sistema de falla Navarro}

Según Montero et al. (1998) presenta un ángulo de inclinación alto y una orientación ENE. Se presenta como un sistema de fallas sinestrales, el cual forma una serie de escarpes prominentes en el valle de los ríos Navarro y Macho, mientras al $\mathrm{N}$ del cuadrante Tapantí su expresión morfológica se ve disminuida, debido al recubrimiento generado por las unidades geológicas asociadas al frente volcánico actual. Se determinó que las fallas asociadas a este sistema desplazan varias unidades geológicas en el valle del río Navarro la separación horizontal de la Formación San Miguel es de al menos 600 m.

\section{Falla Purisil}

Sojo (2015) propone esta falla, la cual se muestra paralela a la traza de la falla Navarro. Tiene un movimiento sinestral, una longitud mayor de $35 \mathrm{~km}$ (continúa al $\mathrm{W}$ y al $\mathrm{E}$ del cuadrante Tapantí), una traza semirectilínea, la cual presenta al menos dos saltos (Purisil y Cerro Belén). En apariencia, su plano es subvertical, y al E del cuadrante su morfología se curva, lo que se asocia con un comportamiento inverso en este sector (Fig. 8 y Mapa Geológico).

\section{Fallas con orientación NW}

Al W del cuadrante Tapantí, fallas presenta una estructura con rumbo NW y con movimiento 


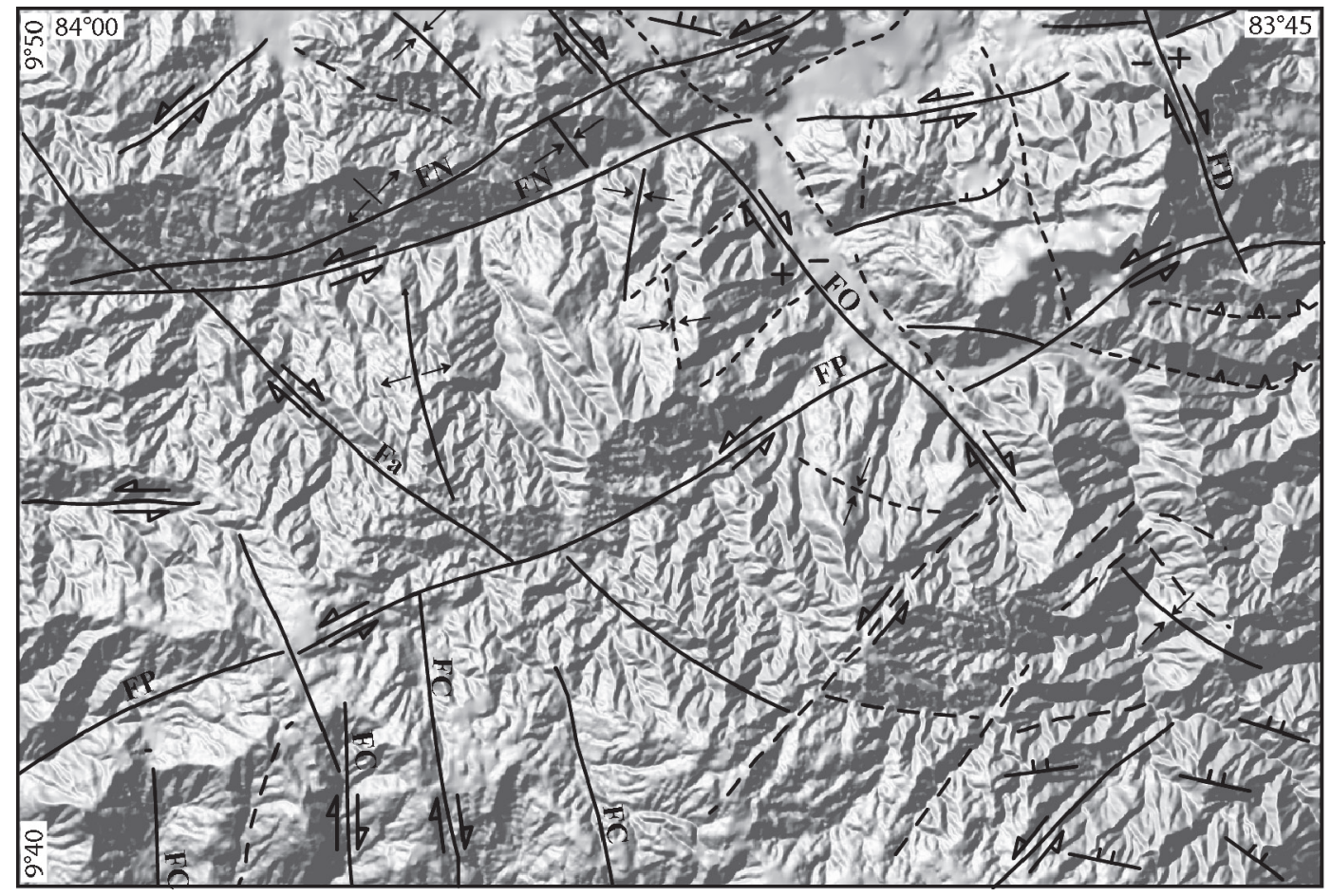

Fig. 8: Estructuras del cuadrante Tapantí. FN; Falla Navarro, FP; Falla Purisil, FD; Falla Doán, FC; Falla Chonta, FO; Falla Orosi, Fa; Falla a.

horizontal, mientras que al NE del área de estudio el fallamiento presenta su mayor expresión con la falla Orosi y Doán, las cuales se orientan al NWN (Fig. 8 y Mapa Geológico).

\section{Falla a}

Su traza se ubica al NW del cuadrante Tapantí y es una estructura con movimiento dextral, traza rectilínea, un plano inclinado hacia el NE, y muestra una longitud de $16 \mathrm{~km}$. Se encuentra cortada por las trazas de fallas con orientación ENE, y pone en contacto a la Formación Pacacua con la Formación La Cruz, según la expresión morfológica en el lugar (Fig. 8 y Mapa Geológico).

\section{Falla Orosi}

La falla Orosi toma gran relevancia en el área de estudio debido a la magnitud de su separación, la cual hace que el bloque situado al E del plano de falla muestre una litología diferente a la litología del bloque W. Esta falla es rectilínea, con una longitud de al menos $12 \mathrm{~km}$ y tiene un plano inclinado hacia el $\mathrm{E}$, que evidencia por medio de morfologías de actividad neotectónica. Muestra un movimiento horizontal mínimo de $600 \mathrm{~m}$ y un desplazamiento vertical cercano a los $500 \mathrm{~m}$, estimado según el escarpe (Fig. 8 y Mapa Geológico).

\section{Falla Doán}

Presenta evidencias de un movimiento horizontal fuerte, el cual se ve reflejado en un escarpe prominente de al menos $300 \mathrm{~m}$ de altura. Su traza rectilínea está orientada al NNW, con longitud de $8 \mathrm{~km}$ y desaparece abruptamente al $\mathrm{N}$ y al S, justamente al topar con las trazas de las fallas Navarro y Río Macho, lo cual podría sugerir algún tipo de asociación entre estas estructuras (Fig. 8 y Mapa Geológico). Esta falla presenta varias morfologías 
neotectónicas, donde sobresalen escarpes de falla poco erosionados, facetas triangulares, aluvión represado, cauces abandonados, cerros aislados, divisorias desplazadas, entre otros.

\section{Fallas con orientación NS}

Berrangé y Wittaker (1977) reportan por primera vez la existencia de este grupo de fallas presentes en el sector SW del cuadrante Tapantí y afirman que se trata de fallas normales. En el presente trabajo se consideran algunas de las trazas propuestas por Berrangé y Wittaker (1977). Se proponen algunas trazas más. Según las morfologías observadas, tanto en el campo como en las fotografías aéreas, presentan un movimiento dextral con componente vertical. Sus trazas son rectilíneas y alcanzan hasta los $8 \mathrm{~km}$ de longitud en el área de estudio, sin embargo, se pudo reconocer que sus trazas se extienden hacia el $\mathrm{S}$ en el cuadrante Vueltas. En el campo se observaron morfologías como cauces alineados, escarpes rectilíneos, aluvión represado y divisorias alineadas (Fig. 8 y Mapa Geológico).

\section{Plegamiento Orosi-Patarrá}

Fernández y Madrigal (1960) describen la estructura geológica del anticlinal de Patarrá, al SE del cuadrante Abra, mientras que Arias y Denyer (1991) relacionan dicha estructura con un periodo de deformación ocurrido a finales del Mioceno Superior. Según lo expuesto por los trabajos anteriores y por los resultados obtenidos durante el presente trabajo, se propone la nomenclatura de Zona de Plegamiento Orosi-Patarrá, compuesta por una serie de anticlinales y sinclinales ubicados en los cuadrantes Abra, Istarú y Tapantí. Los datos de este plegamiento sugieren una zona de pliegues orientados NWSE, provocados posiblemente por esfuerzos NS a NE-SW (Fig. 8) y que muestran una posible continuación al SE del cuadrante Tapantí, en los cuadrantes Vueltas, Pejibaye y Cuericí. El periodo de deformación, donde se originan los pliegues, se desarrolló posiblemente entre los 10 y $6 \mathrm{Ma}$, debido a que afecta a litologías del Mioceno Superior como Formación La Cruz, San Miguel y es anterior a la Formación Grifo Alto (6 Ma, Alvarado y Gans, 2012).

\section{Anticlinales}

Se identificó un anticlinal en las cercanías del poblado de Muñeco, el cual se encuentra cortado por la falla Navarro. Se trata de una estructura con un eje axial orientado $\mathrm{N} 3^{\circ} \mathrm{W}$, relativamente simétrico, con una extensión longitudinal de al menos $8 \mathrm{~km}$ y vergencia al $\mathrm{N}$. Es un pliegue abierto, con ancho cercano a los $6 \mathrm{~km}$. Hacia el centro del pliegue se encuentra aflorando la Formación Pacacua, mientras que hacia los flancos aflora la Formación Peña Negra. El segundo segmento de dicho pliegue se encuentra $1 \mathrm{~km}$ al $\mathrm{N}$ del poblado de Muñeco, presenta un eje axial orientado al $\mathrm{N} 45^{\circ} \mathrm{W}$ y al igual que el segmento anterior, es simétrico, con una extensión longitudinal de 1,4 km. Dicho pliegue se extiende por $6 \mathrm{~km}$, es abierto hacia el centro afloran rocas de la Formación Peña Negra y hacia sus flancos rocas de la Formación Coris.

\section{Sinclinales}

Se cartografiaron 2 sinclinales, uno en Navarro y el otro en el Parque Nacional Tapantí. El sinclinal ubicado al $\mathrm{N}$ del área del cuadrángulo está segmentado en 3 partes por la acción del Sistema de Falla Navarro. Se observa en el camino que comunica el embalse de Río Macho con la localidad de Puente Negro y en el camino que comunica al sector de Río Perlas con Navarro. Presenta una orientación de su eje axial N-S, es asimétrico, con plano axial inclinado con dirección $\mathrm{N}-\mathrm{S}$, inclinado $75^{\circ}$ al $\mathrm{W}$, tiene una longitud de $13 \mathrm{~km}$ y un ancho de $8 \mathrm{~km}$. En el flanco W está compuesto por rocas de la Formación Peña Negra, la cual presenta inclinaciones promedio de $\mathrm{N} 15^{\circ} \mathrm{W}, 30^{\circ}$, hacia la charnela afloran rocas de la Formación Coris, que presenta inclinaciones bajas $\left(\mathrm{N}, \mathrm{N} 20^{\circ} \mathrm{W}, 15^{\circ}\right.$, $\mathrm{N} 20^{\circ} \mathrm{W}, 15^{\circ}$ ), mientras que el flanco E está compuesto por rocas de la Formación Peña Negra 
y la Formación San Miguel (Mioceno MedioSuperior), con inclinación promedio $\mathrm{N} 70^{\circ} \mathrm{W}, 25^{\circ}$.

Finalmente, en el camino que comunica al Parque Nacional Tapantí con la Reserva Río Macho, se determinó la existencia de un sinclinal con un eje axial de $\mathrm{N} 40^{\circ} \mathrm{W}$, extensión longitudinal de al menos $14 \mathrm{~km}$, asimétrico, con un eje axial inclinado $\mathrm{N} 50^{\circ} \mathrm{W}, 80^{\circ}$ y un ancho de $8 \mathrm{~km}$. Ambos flancos están compuesto por rocas de las formaciones Pacacua y Peña Negra, mientras que hacia la charnela aflora el Intrusivo de Tapantí (Plioceno).

\section{Basculamiento de Paraíso}

Tanto en el cuadrante Tapantí, como al SE del cuadrante Istarú, se determinó que la Formación Paraíso se encuentra basculada entre 2 y $3^{\circ}$, mostrando una planicie con una inclinación ENE que no corresponde con lo esperado (un ángulo de depositación primaria inclinado al SW). Por lo tanto, se infiere un basculamiento general mayor a $3^{\circ}$. Según la edad de esta formación $(0,6 \mathrm{Ma})$ y su inclinación actual se interpreta un movimiento de 1\%50 000 .

\section{CONCLUSIONES}

En el cuadrante Tapantí existe un registro de 3 arcos volcánicos; el del Mioceno, que está representado por clastos en la Formación Pacacua y los productos volcánicos de la Formación La Cruz, en segundo lugar, las formaciones Grifo Alto y Doán representan el vulcanismo del Plioceno y, por último, las formaciones Paraíso y Cervantes forman parte del arco volcánico actual.

Se observa un fuerte cambio en la composición del magmatismo hacia los 10 - $6 \mathrm{Ma}$, lo cual se expresa principalmente por el enriquecimiento de $\mathrm{K}$ y Si, y los cambios en la concentración de $\mathrm{U}, \mathrm{Sr}, \mathrm{Ba}, \mathrm{La}$. Ello corresponde temporalmente con el arribo de la cordillera de Coco a la Fosa Mesoamericana (Gazel et al., 2009) y es reflejado en la región por el establecimiento del arco volcánico del Plioceno, el Intrusivo de Tapantí (Plioceno) y el arco volcánico actual.

Las rocas sedimentarias presentes en el área de estudio se asocian principalmente a la cuenca de Candelaria, donde coexistió un abanico deltáico (Formación Pacacua), una plataforma anóxica (Formación Peña Negra) con gradación hacia una plataforma carbonatada (Formación San Miguel), que gradó a un ambiente litoral (Formación Coris). En general, la cuenca estuvo influenciada por vulcanismo cercano a la costa, que debió de tener una elongación SE-NW, limitada al W por la Formación Tulín (Denyer, Baumgartner y Gazel, 2006) y al E por el arco volcánico del Oligoceno-Mioceno Superior.

El arco volcánico del Mioceno Superior, se caracteriza por su composición básica a intermedia y presenta una clara tendencia toleítica. Se asocia a una fuente magmática MORB, debido a los bajos valores de $\mathrm{K}$ y $\mathrm{SiO} 2$ y un patrón de REE semiplano, lo que contrasta con los patrones de los arcos volcánicos posteriores, (según relaciones $\mathrm{Zr} / \mathrm{Nb}$ vs $\mathrm{Ba} / \mathrm{La}$ ).

El arco volcánico del Plioceno, al igual que el Intrusivo Tapantí, se asocian a series calco-alcalinas y calco-alcalinas con alto $\mathrm{K}$, que muestran una relación de $\mathrm{SiO} 2$ vs. $\mathrm{MgO}$ de $50 \%$ y patrones planos de REE con pendiente fuerte, lo que se interpreta como un enriquecimiento de una fuente mantélica. Además, este arco tiene valores bajos en la relación $\mathrm{Zr} / \mathrm{Nb}$ vs $\mathrm{Ba} / \mathrm{La}$, que se asocian a una fuente mantélica OIB y presenta concentraciones de $\mathrm{U}$ menores a 0,5 , lo que sugiere una disminución del aporte sedimentos pelágicos al magma.

El modelo estructural sugiere la existencia de dos episodios de deformación a partir del Mioceno Superior y hasta la actualidad. El primero ocurrió durante el periodo comprendido entre el Mioceno Superior y el Plioceno y produjo el rápido levantamiento y deformación de los sedimentos, lo cual se refleja en la Zona de Plegamiento OrosiPatarrá. El segundo corresponde con la instauración y desarrollo del CDCCR, probablemente desde el Plioceno hasta la actualidad.

El CDCCR genera en el cuadrante Tapantí fallas con orientación ENE, NW y N-S. Las fallas ENE son las más importantes, son sinestrales y presentan varios relevos, lo que ha generado depresiones o cuencas como Ujarrás y Cachí o Purisil (transtensivo).

La Formación Paraíso (0,6 Ma), se encuentra basculada (como mínimo) más de $3^{\circ} \mathrm{N}$, lo cual muestra el grado de afectación por parte del 
CDCCR en la región. De ser así y de haber mantenido una taza de rotación constante, se puede interpretar un movimiento de aproximadamente $1 \% 50000$ años.

\section{AGRADECIMIENTOS}

Al proyecto de investigación 83-B0-242 del Centro de Investigación en Ciencias Geológicas de la Vicerrectoría de investigación de la UCR por el financiamiento, a la CNE por el transporte, al personal del ICE por facilitar la entrada a sus instalaciones, a la empresa GEOTEST SA., por su colaboración en insumos. Al Parque Nacional Tapantí por su colaboración. Los análisis geoquímicos se hicieron en los laboratorios del Departamento de Geociencias del Virginia Tech (USA).

\section{REFERENCIAS BIBLIOGRÁFICAS}

Aguilar, D. A. (1984). Sismicidad del 3 al 9 de setiembre de 1980 y su relación con la geología de la cabecera del rio Navarro, Cartago (tesis de licenciatura inédita). Universidad de Costa Rica, San José, Costa Rica.

Alvarado, M. E. (1982). Estudios sedimento lógicos en la Formación Pacacua (Mioceno, CR) (tesis de licenciatura inédita). Universidad de Costa Rica, San José, Costa Rica.

Alvarado, G. E., Carr, M., Turrin, B., Swisher, C., Schmincke, H. y Hudnut, K. (2006). Recent volcanic history of Irazú volcano, Costa Rica: Alternation and mixing of two intracrustal chambers. En W. Rose, G. Bluth, M. Carr, J. Ewert, L. Patino y J. Vallance (eds), Natural Hazards in Central America (pp. 259-276). Geological Society of America 412.

Alvarado, G. E. y Gans, P. (2012). Síntesis geocronológica del magmatismo, metamorfismo y metalogenia de Costa Rica,
América Central. Revista Geológica de América Central, 46, 7-122.

Alvarado, G. E. y Perez, W. (1998). The Doán formation (Pliocene) of Costa Rica: an overview on its description, origin, lateral equivalents, and further implications on the closing of the Central America seaway. En S. Nishimura (ed), Sixth International Congress on Pacific Neogene Stratigraphy and IGCP-355 (pp. 150-167). Proceedings.IGCP.

Alvarado, G. E. y Vega, E. (2013). La geomorfología de las colada de Cervantes, volcán Irazú (Costa Rica): descripción de uno de los campos de lava más grandes de América Central. Revista Geológica de América Central, 48, 99-118.

Arias, O. y Denyer, P. (1990). Geología de la hoja Caraigres (Escala 1:50 000). San José: IGN.

Badilla, E., Linkimer, L. y Zúñiga, H. (1999). Geología de Navarro y alrededores, provincia de Cartago Costa Rica. San José: Universidad de Costa Rica. Informe de campaña geológica.

Bellon, H. y Tournon, J. (1978). Contribution de la geóchronométric K-Ar á l'étude du magmatisme de CR., Amérique Central. Bulletin de la Société Géologique de France, 7-XX(6), 955-959.

Bergoeing, J. P. (1982). Dataciones radiométricas en algunas muestras de Costa Rica. Informe Semestral del IGN, 1, 71-86.

Berrangé, J. P. y Wittaker, J. E. (1977). Reconnaissance Geology of the Tapanti Quadrangle, Talamanca Cordillera, Costa Rica. Londres: Institute of Geological Sciences, Overseas Division.

Bolz, A. y Calvo, C. (2002). Calizas Lutetianas del Arco Interno Paleoceno de Costa Rica. Revista Geológica de América Central, 26: 7-24. 
Bottazzi, G. (2016). Tratado de sedimentología de la Cuenca Limón Sur - Costa Rica: Evolución tecto-sedimentaria, secuencias y reconstrucción paleogeográfica (tesis de licenciatura inédita). Universidad de Costa Rica, San José, Costa Rica.

Boynton, W. V. (1984). Cosmochemistry of the rare earth elements: meteorite studies. En P. Henderson (ed.), Rare Earth elements Geochemistry (pp. 63-114). Amsterdam: Elsevier.

Cameron, B. I., Walter, J. A., Carr, M. J., Patino, L. C., Matias, O. y Feigenson, M. D. (2002). Flux versus decompression melting at stratovolcanoes in southeastern Guatemala. Journal of Volcanology and Geothermal Research, 119, 21-50.

Carballo, M. A. (1978). La Formación San Miguel, Mioceno inferior, Costa Rica (tesis de licenciatura inédita). Universidad de Costa Rica, San José, Costa Rica.

Carr, M. J., Feigenson, M. D. y Bennett, E. A. (1990). Incompatible element and isotopic evidence for tectonic control of source mixing and melt extraction along the Central American arc. Contributions to Mineralogy and Petrology, 105, 369-380.

Castillo, R., 1969: Geología de los mapas básicos de Abra y parte de río Grande, Costa Rica.Informes técnicos y notas geológicas. Ministerio de Industria y Comercio, Dirección de Geología, Minas y Petróleo, $33,1-40$.

Crosby, I. B. (1945). Geología del cañón del río Virilla, en la meseta central Occidental de Costa Rica (traducción de F. Gutiérrez). Boletín Técnico del Departamento Nacional de Agricultura, 49, 1-19.

Dengo, G. (1962). Tectonic-igneous sequence in Costa Rica. En A. E. J. Engel, H. L. James y B. F. Leonard (eds), Petrologic studies: a volume in honor of A. F. Buddington (pp. 133-161). Boulder, Colorado: Geological Society of America.

Dengo, G. y Chaverri R. G. (1951). Reseña geológica de la región sudoeste de la meseta Central de Costa Rica. Revista UCR, 5 313-326.

Denyer, P. y Arias, O. (1991). Estratigrafía de la región central de Costa Rica. Revista Geológica de América Central, 12, 1-59.

Denyer, P. y Alvarado, G. E. (2007). Mapa geológico de Costa Rica (Escala 1:400 000). San José: Librería Francesa.

Denyer, P., Baumgartner, P. y Gazel, E. (2006). Emplacement of Jurassic-Lower Cretaceous radiolarites of the Nicoya Complex (Costa Rica). Geologica Acta, 4(1-2), 203-218.

Denyer, P., Montero, W. y Alvarado, G. E. (2009). Atlas tectónico de Costa Rica (2 ${ }^{\mathrm{da}}$ edición). San José: Ed. UCR.

Dóndoli, C. y Chaves, R. (1968). Mapa adjunto al estudio geológico del Valle Central (Escala 1: 150 000). San José: IGN.

Dóndoli B., C. y Torres A, C. (1954). Estudio geo-agronómico de la región oriental de la Meseta Central. Ministerio de Agricultura e Industria, 11-47.

Escalante, G. (1966). Geología de la cuenca superior del río Reventazón, Costa Rica. Publicaciones Geológicas del ICAITI, 1, 59-70.

Fernández, M. y Madrigal, R. (1960). Calcáreos y calizas de la zona de Patarrá. Informes MEIC, 4, 1-17.

Fischer, R. y Franco A. J. C. (1979). La Formación Coris (Mioceno, Valle Central, CR). Informe Semestral del IGN, 1, 15-71. 
Gazel, E., Alvarado, G. E., Obando, J. y Alfaro, A. (2005). Evolución magmática del arco de Sarapiquí, Costa Rica. Revista Geológica de América Central, 32, 13-31.

Gazel, E., Carr, M., Hoernle, K., Feigenson, M. D., Szymanski, D., Hauff, F. y Bogaard, P. (2009). Galápagos-OIB signatures in southern Central America: Mantle refertilization by arc-hot spot interaction. Geochemistry Geophysics Geosystems, 10(2), 1-32.

Gazel, E., Hoernle, K., Carr, M., Herzerg, G., Saginor, I., Vandenbogaard, P. ... Swisher III, C. (2011).Plume subduction interaction in sourthern Central America: Mantle upwelling and slab melting. Lithos, 121, 117-134.

Gazel, E., Hayes, J., Hoernle, K., Kelemen, P., Everson, E., Holbrook, S. ... Yogodzinski, G. (2015). Continental crust generated in oceanic arcs. Nature, 8, 321-328.

Hill, R. T. (1898). The geological history of the isthmus of Panamá and portions of Costa Rica. Bulletin of the Museum of Comparative Zoölogy, XXVIII(5), 151- 285.

Hoffstetter, R., Dengo, G., Dixon, C. G., Meyerabich, H., Wey1, R., Woodring, W. P. y Zoppis Bracci, L. (1960). Lexique stratigrajohique international, vol. 5, 2 a: Amérique Centrale. Paris: Centre National de la Recherche Scientifique.

Irvine, T. N. y Baragar, W. R. A. (1971). A guide to the chemical classification of the common volcanic rocks. Canadian Journal of Earth Sciences, 8, 523-548.

Krushensky. R. D. (1972). Geology of Istarú quadrangle, Costa Rica. U.S. Geological Survey Bulletin, 1358, 1- 46.

Kussmaul, S. (1987). Petrología de las rocas intrusivas Neógenas de Costa Rica. Revista Geológica de América Central, 7, 83-111.
Llambías, E., 2012: Geología de los cuerpos ígneos. Argentina: Instituto Superior de Correlación Geológica (INSUGEO).

Linkimer, L. (2003). Neotectónica del extremo oriental del Cinturón Deformado del Centro de Costa Rica. (tesis de licenciatura inédita). Universidad de Costa Rica, San José, Costa Rica.

Lücke, O. y Arroyo, I. (2015). Density structure and geometry of the Costa Rican subduction zone from 3-D gravity modeling and local earthquake data. Solid Earth, 6, 1169-1183.

Madrigal M. J. (1989). Estudio geológico de una parte de la cuenca del río Tulín, entre el río Galán y la quebrada San Gabriel, San José, Costa Rica. San José: Universidad de Costa Rica. Informe de campaña geológica.

Marshall, J. S. y Fischer, D. (2000). Central Costa Rica deformed belt: kinematics of diffuse faulting across the western Panama block. Tectonics, 19(3), 468-492.

Marshall, J. S., Idelman, B. D., Gardner, T. W. y Fisher, D. M. (2003). Landscape evolution within a retreating volcanic arc, Costa Rica, Central America. Geology, 31(5), 419-422.

Mcdonough, W. F. y Sun, S. (1995). The composition of the Earth. Chemical Geology, 120, 223-253.

MacMillan, I., Gans, P. y Alvarado, G. E. (2004). Middle Miocene to present plate tectonic history of the southern Central American Volcanic Arc. Tectonophysiscs, 392: 325-348.

Miyamura, S. (1975). Recent crustal movement in Costa Rica disclosed by relevelling surveys. Tectonophysics, 29, 191-198.

Montero, W. (2001). Neotectónica de la región central de Costa Rica: frontera oeste de la Microplaca de Panamá. Revista Geológica de América Central, 24, 29-56. 
Mora, R. (2010). Geomorfología y probabilidad de ocurrencia de deslizamientos, Orosi, Paraíso, Cartago. En Peraldo, G. y Acevedo, B. (eds), Efemérides de la destrucción de la ciudad de Cartago cien años después (1910-2010) (pp. 143-150). San José, Ediciones Perro Azul.

Olson, C. y Sáenz, R. (1966). Fotointerpretación de la colada de Cervantes, Costa Rica. Informe Semestreal del IGN, 2, 23-37.

Plank, T., Vaughn, B. y Carr, M. J. (2002). Nicaraguan volcanoes record paleoceanographic changes accompanying closure of the Panama gateway. Geology, 30(12), 1087-1090.

Pearce, J. A. y Norry, M. J. (1979). Petrogenetic Implications of $\mathrm{Ti}, \mathrm{Zr}$, $\mathrm{Y}$ and $\mathrm{Nb}$ Variations in Volcanic Rocks. Contributions to Mineralogy and Petrology, 69(1), 33-47.

Peccerillo, A. y Taylor, S. R. (1976). Geochemistry of Eocene calc-alkaline volcanic rocks from the Kastamonu area, northern Turkey. Contributions to Mineralogy and Petrology, 58(1), 63-81.

Rivier, F. (1979). Geología del área norte de los cerros de Escazú, Cordillera de Talamanca, Costa Rica. Informe Semestreal del IGN, 1, 99-138.

Rivier, F. y Calvo, C. (1988). Terciario del S del Valle Central: sección estratigráfica del cerro Caraigres, prov. San José, Costa Rica. Revista Geológica de América Central, 9, 61-74.

Romanes, J. (1912). Geology of part of Costa Rica. Quarterly Journal of the Geological Society, 68, 103-139.
Salvador, A. (1994). International Stratigrahpic Guide. Boulder, Colorado: The International Union of Geological Sciences.

Salazar, L. G., Obando, L y Mora, R. (1992). Revista Geológica de América Central, 14, 85-96.

Sojo, D. (2015). Modelo geológico del cuadrante Tapantí, Costa Rica (tesis de licenciatura inédita). Universidad de Costa Rica, San José, Costa Rica.

Soto, D. y Alvarado G. E. (2012). Peperitas en Costa Rica. Revista Geológica de América Central, 47, 55-68.

Taylor, G. D. (1975). The geology of the Limon area of Costa Rica (tesis doctorado inédita). Louisiana State University and Agricultural and Mechanical College, Louisiana, Estados Unidos.

Umaña, J. (1966). Geología del sitio de presa del proyecto Cachí, Costa Rica. Publicaciones Geológicas del ICAITI, 1, 27-41.

Valverde, R. (1989). Investigación geológicoambiental del proyecto túnel de Pejibaye, Cartago, Costa Rica (tesis de licenciatura inédita). Universidad de Costa Rica, San José, Costa Rica.

Weyl, R. (1960). Las ignimbritas centroamericanas. Informe Semestral del ING, 1, 39-61.

Winchester, J. A. y Floyd, P. A. (1977). Geochemical discrimination of different magma series and their differentiation products using immobile elements: Chemical Geology, 20, 325-343. 